SANDIA REPORT

SAND9 $1-0867 \cdot \mathrm{UC}-116$

Unlirilted Release

F'rinted September 1991

\title{
Application of a Damage Model for Rock Fragmentation to the Straight Creek Mine Blast Experiments
}

B. J. Thorne

Prepared by

Sandia National Laboratories

Albuquerque, New Mexico 87185 and Livermore, California 94550

for the United States Department of Energy

under Contract DE-AC04-76DP00789 
Issued by Sandia National Laboratories, operated for the United States Department of Energy by Sandia Corporation.

NOTICE: This report was prepared as an account of work sponsored by an agency of the United States Government. Neither the United States Government nor any agency thereof nor any of their em-ioyees, nor any of their contractors, subcontractors, of cheir employees, makes any warranty, express or implied, or assumes any legal liability or responsibility for the accuracy, completeness, or usefulness of any information, apparatus, product, or process disclosed, or represents that ita use would not infringe privately owned rights. Reference herein to any specific commercial product, process, or service by trade name, trademark, manufacturer, or otherwise, does not necessarily constitute or imply its endorsement, recommendation, or favoring by the United States Government, uny agency thereof or any of their contractors or subcontractors. The views and opinions expressed herein do not necessarily state or reflect those of the United States Government, any agency thereof or any of their contractors.

Printed in the United States of America. This report has been reproduced directly from the best available copy.

Available to DOE and DOE contractors from

Office of Scientific and Technical Information

PO Box 62

Oak Ridge, TN 37831

Prices available from (615) 576-8401, FTS 626-8401

Available to the public from

National Technical Information Service

US Department of Commerce

5285 Port Royal Rd

Springfield, VA 22161

NTIS price codes

Printed copy: A03

Microfiche copy: A01 


\begin{abstract}
Early attempts at estimation of stress wave damage due to blasting by use of finite element calculations met with limited success uue to numerical instabilities that prevented calculations from being carried past the fragmentation 1imit. More recently, an improved damage model has allowed finite eiement calculations which remain stable and yield good agreement between calculated fragmented regions and excavated crater profiles for blasting experiments in granite. Application of this damage model to blast experiments at the Straight Creek Mine in Bell County, Kentucky were complicated by anisotropic conditions and uncertainties in material properties. It appears that significant modifications to the damage model and extensive material testing may be necessary in order to estimate damage in these anisotropic materials.
\end{abstract}

\title{
MASTER
}

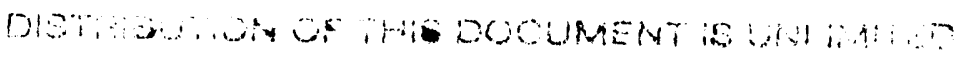


INTENTIONALLY LEFT BLANK 


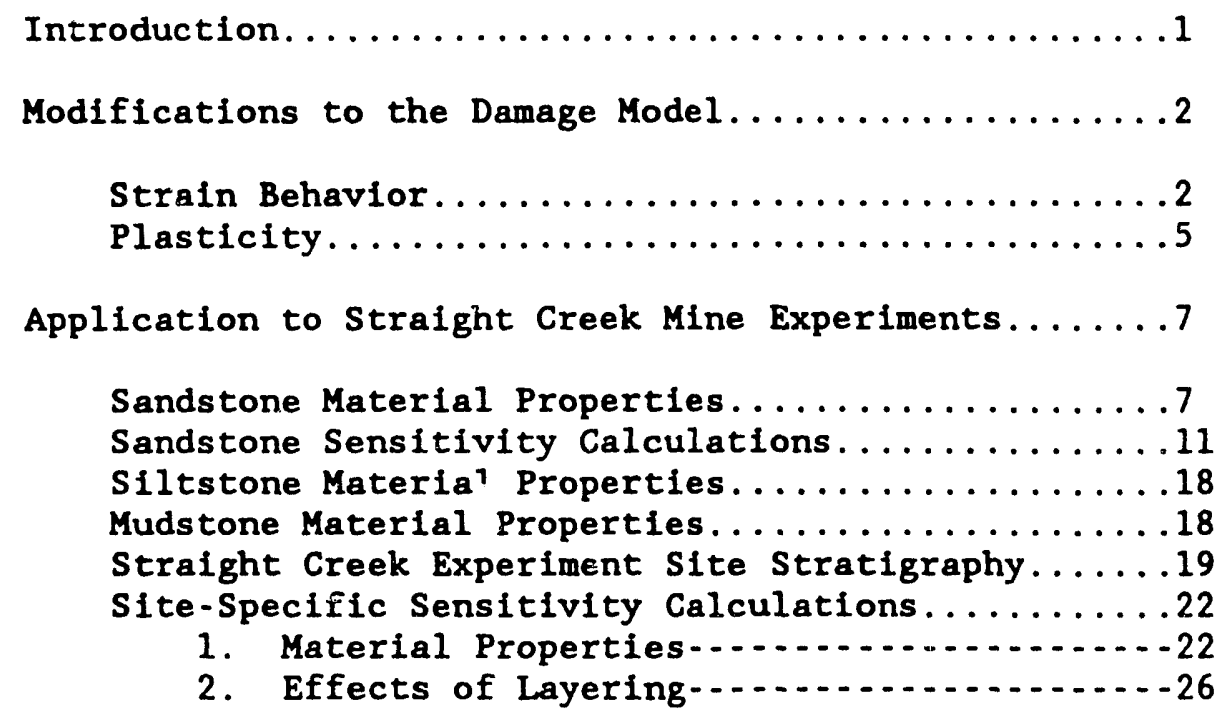

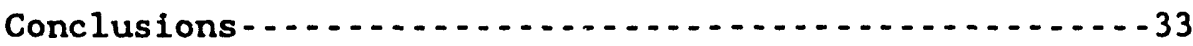

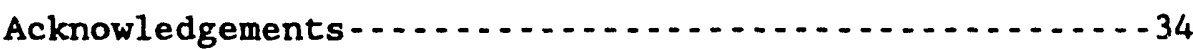

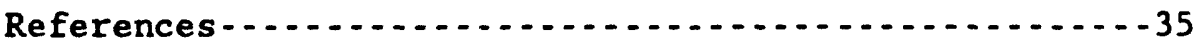

Appendix A-1... Pronto Changes to Implement the New Damage Model

Appendix B-... Damage Model Subroutine 


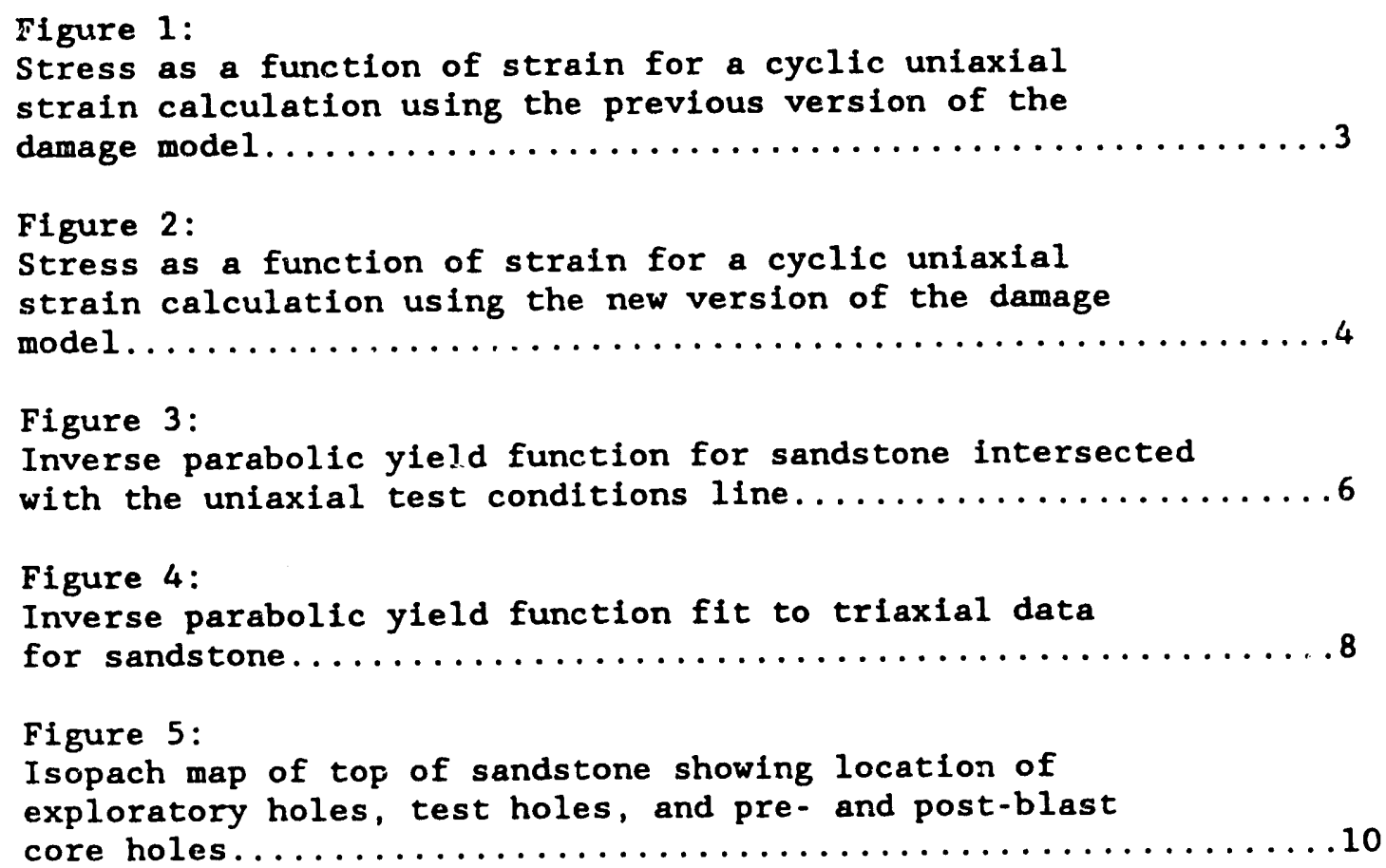




\section{LIST OF FIGURES}

(Continued)

Figure 10:

Schematic diagram of the lithography near the A3D12A

blast experiment borehole.........................20

Figure 11:

Position of explosive charge and material interfaces

in the finite element approximation to the A3D12A blast

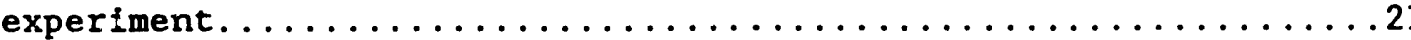

Figure 12:

Calculated fragmented region for the A3D12A blast

experiment using material properties measured by

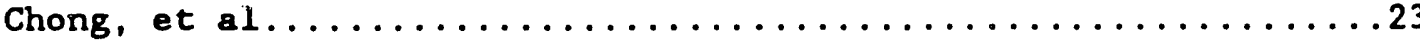

Figure 13:

Calculated fragmented region for the A3D12A blast

experiment using isotropic sandstone material properties

based on horizontal $\mathrm{p}$-wave velocities measured by

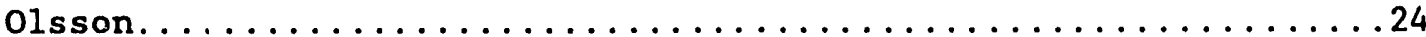

Figure 14:

Calculated fragmented region for the A3D12A blast

experiment using orthotropic sandstone material properties

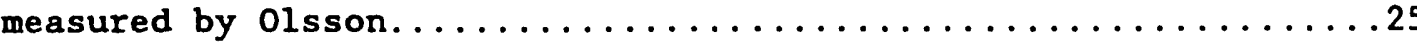

Figure 15:

Calculated fragmented region for the A.3D12A blast

experiment using reduced Young's moduli for siltstone

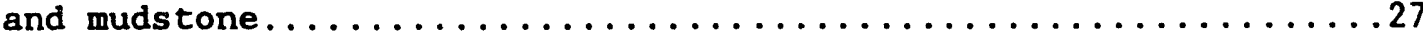

Figure 16:

Calculated fragmented region for the A3D12A blast

experiment including three thin coal seams................29

Figure 17:

Calculated fragmented region for the A3D12A blast

experiment including three thin coal seams and

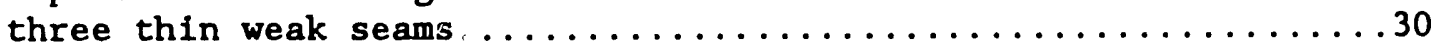

Figure 18:

Calculated fragmented region for the A3D12A blast

experiment including three thin coal seams, three thin

wrak seams and using reduced Young's moduli for the

siltstone and mudstone. 
INTENTIONALLY LEFT BLANK 
For a number of years Sandia National Laboratories has been involved in the development of numerical models for describing blasting processes. This work has developed two separate computational thrusts. The early time stress wave propagation is treated through use of a dynamic finite element computer program, PRONTO $[1,2]$, and a constitutive model which attempts to describe the fracturing which occurs as a result of stress wave induced material deformation. A separate modeling effort $[3,4]$ attempts to describe the motion of the broken rock as a result of gas flow loading.

As part of our numerical model development program, an experimental verification effort has been conducted jointly with Atlas Powiler Company. Beginning in 1988, cratering experiments were conducted for the express purpose of generating data for comparison with model predictions. These experiments examined variations in geometry, rock type and explosive. Data collected include detonation velocity, high-speed photography of ground motion, musk pile profiles, excavated crater profiles and particle size information. These data have been used to guide our current approach and are being used to identify weaknesses which should be talgeted in future research. These studies indicate the complexity of the mechanisms involved and are also serving as a basis for developing complementary numerical descriptions that emphasize alternate physical processes.

The current form of the damage model has evolved over a number of years $[5,6,7,8,9]$. Since stress wave induced fragmentation is a very complex process, any computational algorithm will only approximately represent a fracturing event. It is, therefore, very important that any model be compared in detail against controlled experimental data. The first in a series of blast experiments to provide this data was performed with Atlas Powder Company at the Pamona Quarry near Greensboro, North Carolina. Laboratory tests of granite from this site $[10,11]$ revealed significantly anisotropic properties induced by a foliation at the site. Even though the current form of the damage model assumes homogenous isotropic material properties, it was possible to use this model, with averaged material properties, to calculate fragmented regions in good agreement with excavated craters at this site $[8,9]$.

The second series of blast experiments with Atlas Powder Company was conducted at the Straight Creek Mine near Pineville, Kentucky. Tests of material from this site $[11,12]$ revealed extremely anisotropic conditions induced by closely spaced horizontal bedding planes at the site. All attempts to use averaged properties for this site, as was done with the first series of tests, resulted in calculated fragmented regions which greatly exceeded the size of the excavated craters. Even attempts to use the maximum strengths that could be justified on the basis of the laboratory tests resulted in over-prediction of fragmented regions. This led to a series of material property sensitivity calculations aimed at determining what mechanisms were most important in situations similar to 
the experiments at the Straight Creek Mine site. It is not practical to present the hundreds of calculations involved in this study. This paper will present a few selected calculations in an attempt to illustrate the general trencis.

\section{MODIFICATIONS TO THE DAMAGE MODEL}

Since publication of the analysis of the Pamona Quarry craters [9] several minor modifications to the damage model have been implemented. These are included in the FORTRAN listings in Appendices $A$ and $B$. After each modification all of the calculations for the Pamona Quarry craters were repeated. Only one of these changes resulted in predicted regions of fragmentation significantly different from those documented in the Pamona Quarry report [9]. Two of these modifications are significant enough to demand documentation here.

\section{Strain Behavior}

E. P. Chen pointed out that the cyclic uniaxial strain behavior illustrated by figure 1 (figure 3 of [9]) is at odds with work of Holcomb and Costin $[13,14]$. By using acoustic emissions to detect the onset of microfracturing, they found that microfracturing did not occur in cyclic uniaxial loading until the maximum strain occurring on previous cycles was exceeded. Once the previous maximum strain was exceeded, damage resumed at the same rate which occurred if a sample were taken directly to that strain without cycling.

The cyclic dilatancy strain, $\varepsilon$, was introduced into the damage model equations [9] based on a conviction that strain not contributing to tension should not contribute to damage. Based on Holcomb and Costin's observation, the formulation of the damage model has been modified by always taking $\varepsilon=0$ and not allowing damage to accumulate until the previous maximum volumetric strain is exceeded. For the cyclic uriaxial strain case, this is in agreement with Holcomb and costin's results and yields the cyclic uniaxial response illustrated by figure 2. This modification does not result in any significant changes to the calculated fragmented region profiles for the Pamona Quarry craters [9].

This new formulation of cyclic behavior in the damage model is in agreement with Holcomb and Costin's results only for the uniaxial case. When they applied the second strain cycle in a direction perpendicular to the first, they found that damage began as soon as the strain in that direction became tensile. This indicates that damage is as sensitive to the direction of the strain as it is to the magnitude. The use of the maximum volumetric strain in place of the maximum directional strain in this modification is correct for the uniaxial strain case as noted above. It should also be approximately correct for regions where terisile waves are reflected perpendicular to a free surface, such as near the center of a crater. However, it would become suspect along the edge of a crater where the direct and reflected tensile waves could be propagating in nearly perpendicular directions. For the calculations presented in this paper and the calculations of the Pamona Quarry craters [9], the direct tensile wave in this region was greatly attenuated and negligible damage was calculated until the reflected tensile wave arrived. 


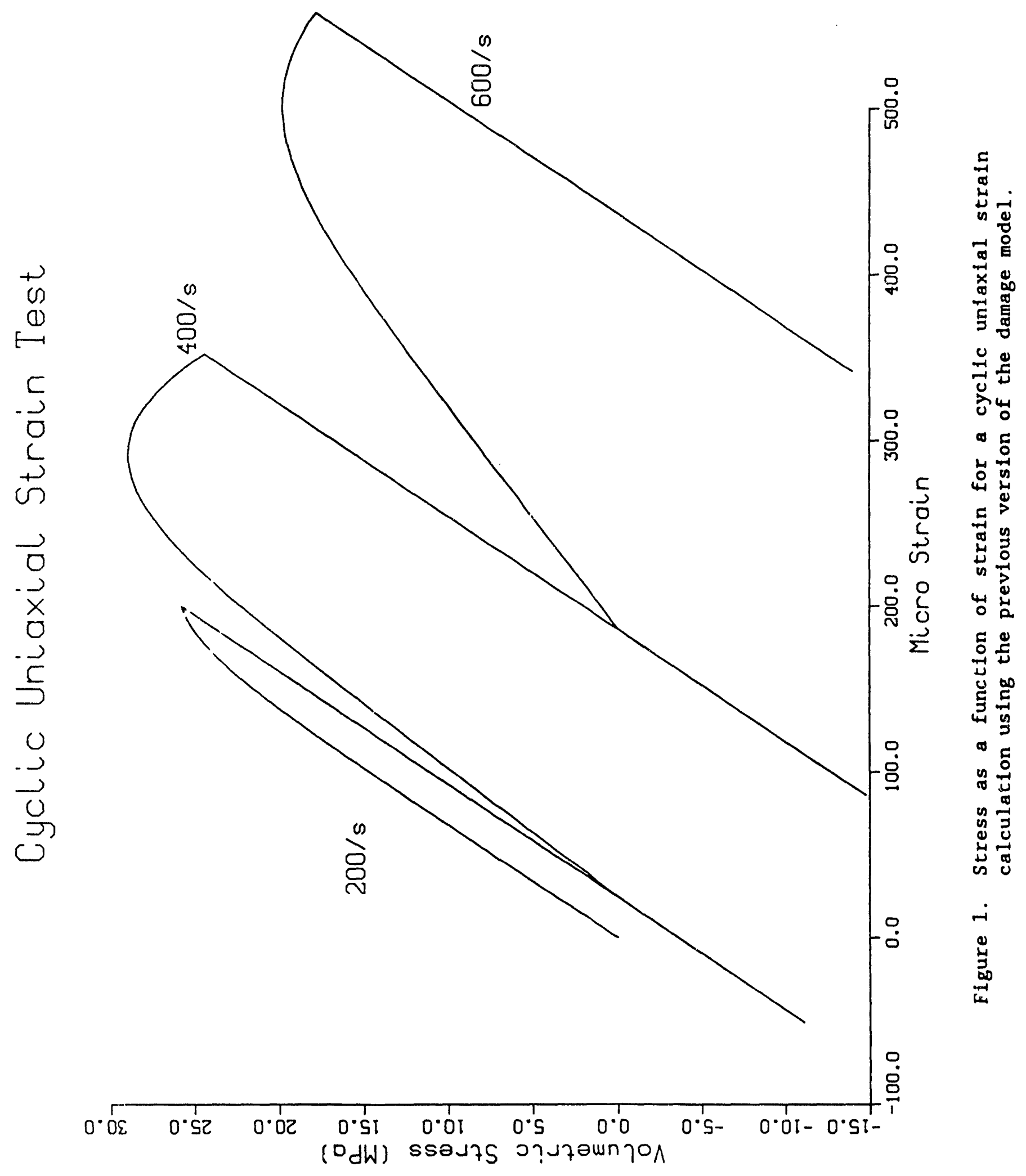




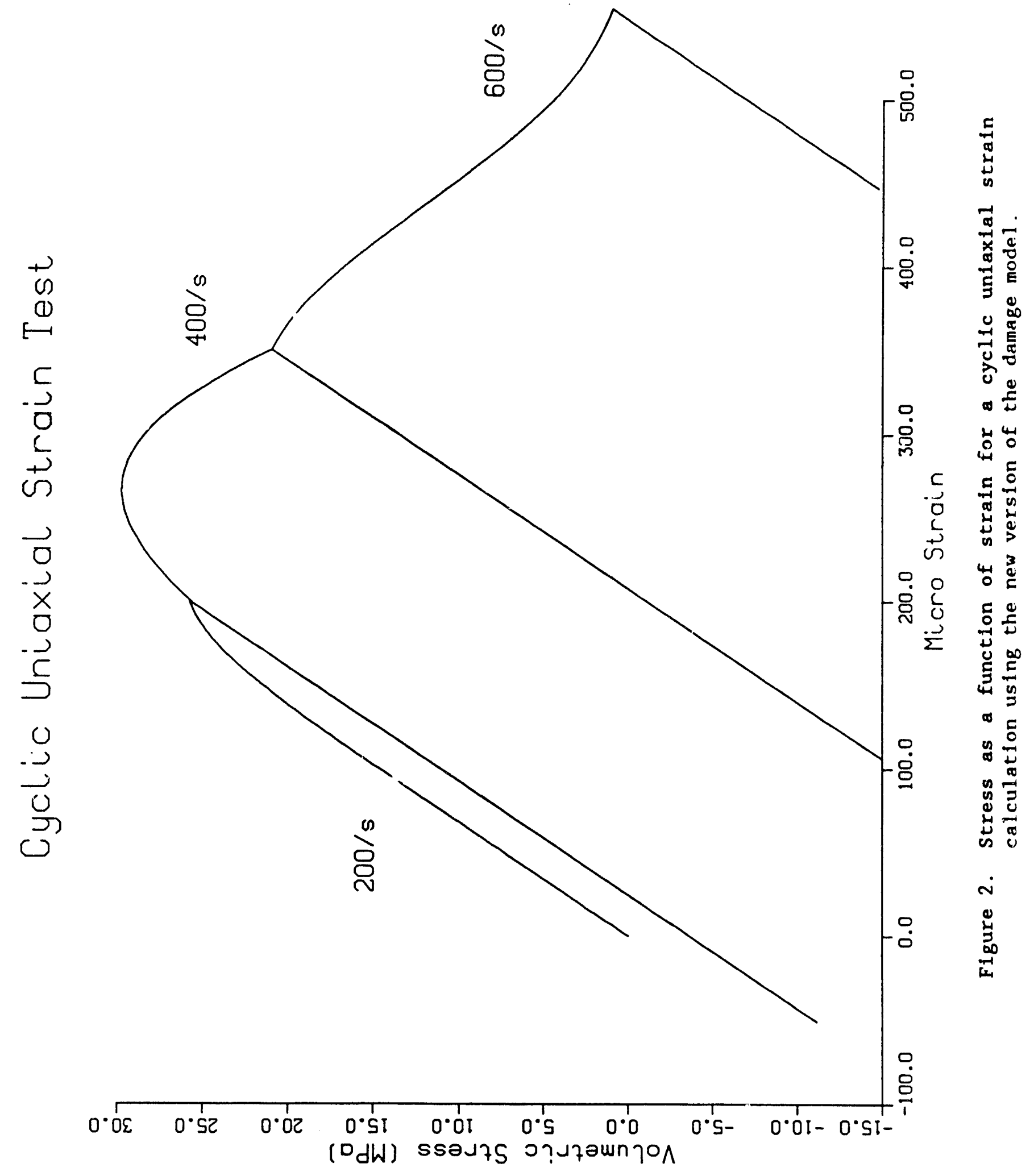


The observation that strain direction is important contradicts the very basis of the current damage model, or any formulation based on volumetric strain. It has long been recognized that damage should depend on the direction of the strain as well as the magnitude. However, all attempts to develop nunierical models which take the strain direction into account (e.g., [15]) have jroven to be complex and have been considered too computationally expensive tor dynamic stress wave calculations. With the current availability of very large, very fast computers, the possibility of developing a dynamic damage model which takes into account the full strain tensor should be vigorously pursued.

\section{Plasticity}

A modif cation to the way plasticity is treated is also included in the FORTRAN listings in Appendices $A$ and $B$. In previous versions of the damage model the yield surface was used as long as the material was in compression. Since the average pressure over a uniaxial test sample is one third of the negative of the axial stress (where pressure is defined to be the negative of the volumetric stress), this allowed yielding to occur at pressures lower than those corresponding to a uniaxial test. This is unrealistic, since yielding in rocks requires high confining pressures. The current version of the damage model computes the intersection of the yield surface with the line corresponding to uniaxial test conditions and does not allow plasticity at pressures below this intersection. For sandstone from the Straight Creek Mine, where triaxial data showing indications of yielding were used to generate the inverse parabola yield surface, this intersection is at a press're of 33MPa (figure 3) and the corresponding yield stress of $99 \mathrm{MPa}$ is approximately what would be expected for failure in a uniaxial test. However, for the Pamona Quarry calculations [9], where no yield data were available and a yield surface was constructed above the failure strength data, this intersection is at a pressure of 200MPa corresponding to a yield stress of $600 \mathrm{MPa}$, more than 4.5 times the uniaxial failure strength measured for this material.

As might be expected, this modification made little difference in sandstone calculations. However, it dramatically increased the computed damage around the explosive charge and reduced both the radius and depth of the calculated fragmented region for the Pamona Quarry calculations. In fact, it was not possible to construct a yield surface which was above the average failure strengths of the granite from the Pamona Quarry experiment site and also resulted in calculated fragmented regions in agreement with the field data when this modification was included in the damage model. The main validation of the current damage model was the successful application to the Pamona Quarry granite calculations [9]. It now appears that these results were dependent on assumptions about plasticity which were probably incorrect. This indicates that proper treatment of the material behavior near the explosive charge is critical in this type of calculation. The current plasticity treatment was only intended to be an approximation. It is apparently not an adequate substitute for a comprehensive theory of the behavior of the material near the explosive charge. 


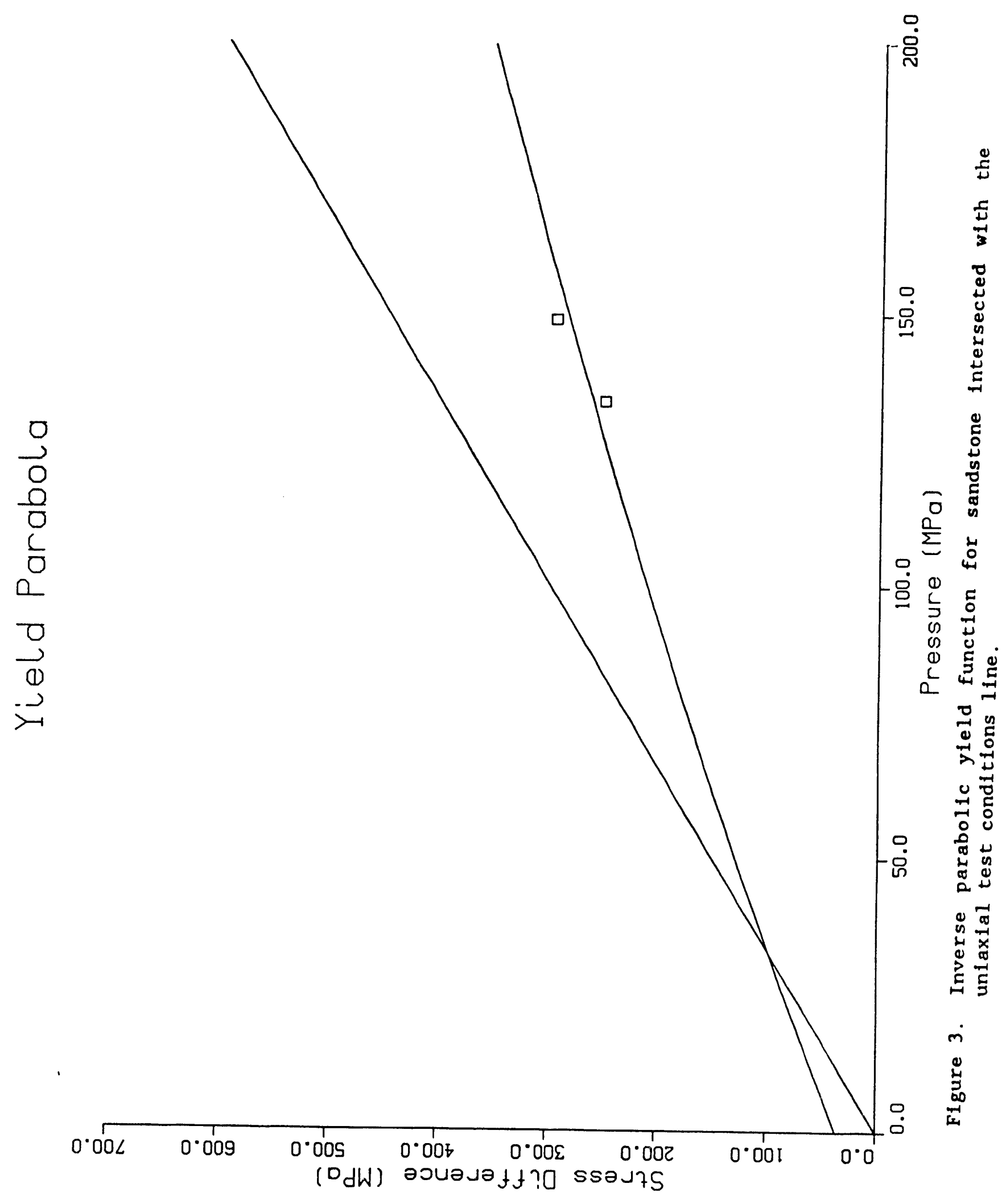




\section{APPLICATION TO STRAIGHT CREEK MINE EXPERIMENTS}

The Straight Creek Mine experiment site is typical of a coal overburden. Sandstone, siltstone and mudstone have been identified as the three main material types. For the purpose of these calculations, the site will be assumed to be made up of thick deposits of these three materials. However, this is only an idealization as there are many bedding planes within each material. In the sandstone, closely spaced irregular horizontai dark-colored streaks define the sandstone bedding. The siltstone is divided into layers several millimeters thick. Even thinner layers, with poor cohesion between them, divide the mudstone. This is further complicated by thin coal seams. [16]

\section{Sandstone Material Properties}

Olsson [11] reports properties measured on nine sandstone samples from the Straight Creek Mine experiment site. These samples gave an average density of $2,589 \mathrm{~kg} / \mathrm{m}^{3}$ with standard deviation $28 \mathrm{~kg} / \mathrm{m}^{3}$. A significant anisotropy is indicated by measurements of $p$-wave velocity on these nine samples. Vertical p-wave velocity averaged $2,800 \mathrm{~m} / \mathrm{s}$ with standard deviation $40 \mathrm{~m} / \mathrm{s}$. Horizontal p-wave velocity averaged $3,390 \mathrm{~m} / \mathrm{s}$ with standard deviation $200 \mathrm{~m} / \mathrm{s}$. Two triaxial tests at each of the confining pressures 50MPa, 100MPa and 200MPa were performed on six of these samples with the sample axis aligned in the vertical direction. For one of the tests at the $100 \mathrm{MPa}$ confining pressure, no Young's modulus or Poisson's ratio was reported. The other fi.e triaxial tests gave an average Young's modulus of $16.3 \mathrm{GPa}$ with standard deviation $2.6 \mathrm{GPa}$ and an average Poisson's ratio of 0.112 with standard deviation 0.011 . Using the 0.112 Poisson's ratio from the triaxial tests, the average p-wave velocities imply a Young's modulus of $28.9 \mathrm{GPa}$ in the horizontal direction and $19.7 \mathrm{GPa}$ in the vertical direction. For the vertical direction, this is only 1.3 standard deviations above the 16.3GPa Young's modulus indicated by the triaxial tests.

If it is assumed that the triaxial test samples are in a uniform stress state at peak stress difference, then the stress differences at peak stress can be plotted as a function of the pressure at peak stress, as in figure 4. The average stress differences at peak stress for these three confining pressures determine an inverse parabola, figure 4, which can be used as a yield surface for finite element calculations. As was previously noted, the finite element calculations allow plasticity only at pressures greater than those corresponding to uniaxial test conditions (figure 3).

Chong et al [12] report both $p-r$ ve and $s$-wave measurements in the vertical direction for ten sandstone sa.ples from the Straight Creek Mine experiment site. For these samples, the average $p$-wave veiocity was $4,558 \mathrm{~m} / \mathrm{s}$ with standard deviation $437 \mathrm{~m} / \mathrm{s}$, much greater than the value obtained by 0lsson. The average s-wave velocity was $2,453 \mathrm{~m} / \mathrm{s}$ with standard deviation $168 \mathrm{~m} / \mathrm{s}$. These velocities imply a Poisson's ratio of 0.296 with standard deviation 0.064 . Density and porosity were measured 


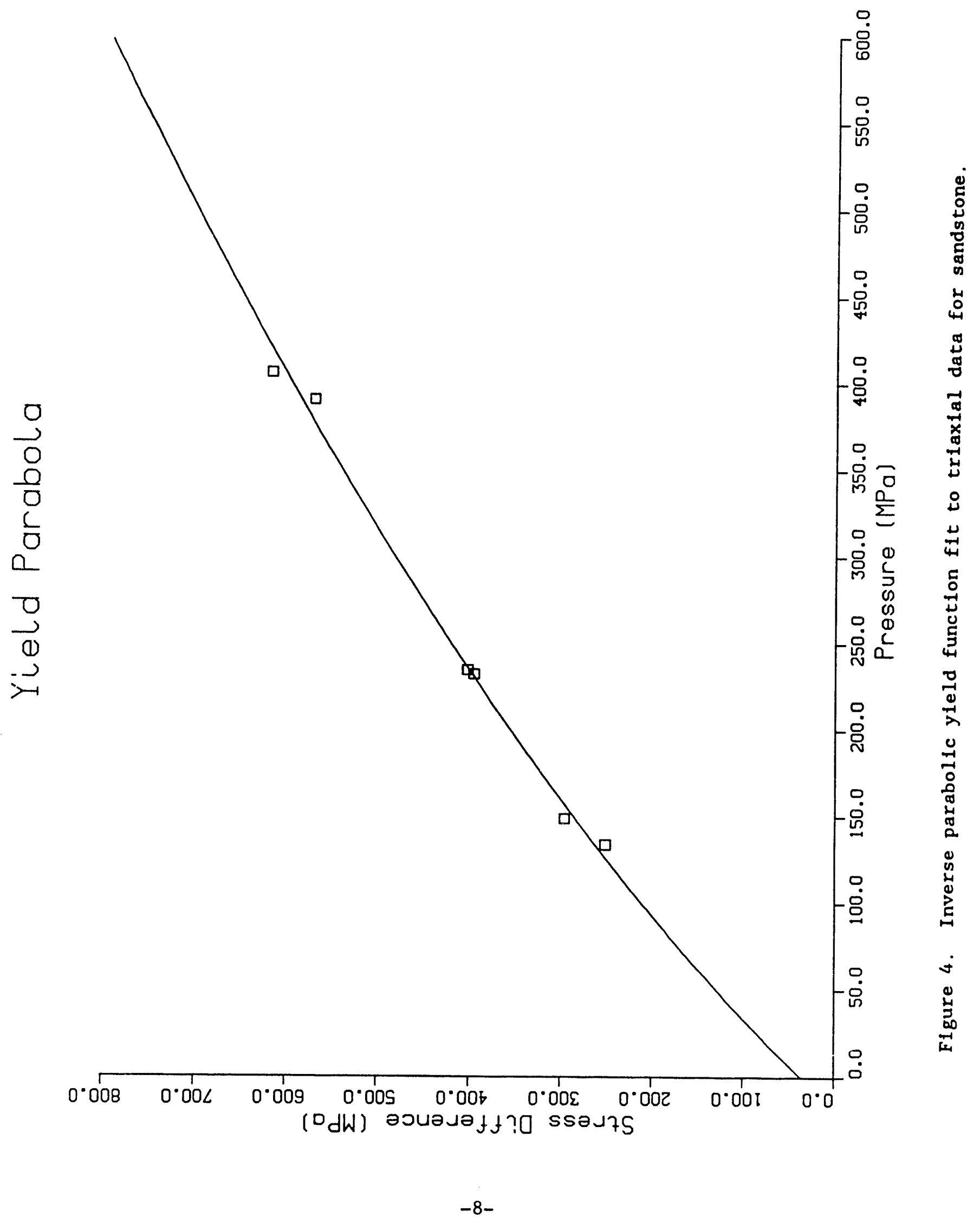


on nine samples and resulted in an average density of $2,680 \mathrm{~kg} / \mathrm{m}^{3}$ with standard deviation $20 \mathrm{~kg} / \mathrm{m}^{3}$ and a porosity of 4.798 with standard deviation 0.268 . This implies a solid material density of $2,815 \mathrm{~kg} / \mathrm{m}^{3}$, which seems high for a sandstone. For a material with $2,680 \mathrm{~kg} / \mathrm{m}^{3}$ density, the ten $p$-wave and $s$-wave velocity pairs imply an average Young's modulus of $41.48 \mathrm{GPa}$ with standard deviation $5.51 \mathrm{GPa}$. Fourteen semi-circular bend specimens gave an average $K$ in the horizontal direction of $711 \mathrm{KPa} / \mathrm{m}$ with standard deviation $151 \mathrm{KPa} / \mathrm{m}$ and twelve chevron bend specimens gave an average $k$ in the vertical direction of $703 \mathrm{KPa} / \mathrm{m}$ with standard deviation $108 \mathrm{KPa} / \mathrm{m}$. These two data sets can be combined to give a direction independent $\mathrm{K}$ of $707 \mathrm{KPa} / \mathrm{m}$ with standard deviation $132 \mathrm{KPa} / \mathrm{m}$.

In terms of the material properties needed for input to the damage model, these two data sets can be summarized as follows:

\section{SANDSTONE}

DENSITY

YOUNG'S MODULUS

POISSON'S RATIO

FRACTURE TOUGHNESS

YIELD PARAMETERS

\begin{tabular}{|c|c|c|}
\hline & Chong & Olsson \\
\hline$\rho$ & $2,680 \mathrm{~kg} / \mathrm{m}^{3}$ & $2,589 \mathrm{~kg} / \mathrm{m}^{3}$ \\
\hline $\mathrm{E}_{\mathrm{v}}$ & $41.48 \mathrm{GPa}$ & $19.7 \mathrm{GPa}$ \\
\hline$E_{B}$ & & $28.9 \mathrm{GPa}$ \\
\hline$\nu$ & 0.296 & 0.112 \\
\hline $\mathrm{K}$ & $707 \mathrm{KPa} / \mathrm{m}$ & \\
\hline CP1 & & $50 \mathrm{MPa}$ \\
\hline Y1 & & $274 \mathrm{MPa}$ \\
\hline CP2 & & $100 \mathrm{MPa}$ \\
\hline Y2 & & $400 \mathrm{MPa}$ \\
\hline CP3 & & $200 \mathrm{MPa}$ \\
\hline Y3 & & $594 \mathrm{MPa}$ \\
\hline
\end{tabular}

(Vertical)

(Horizontal)

The material properties obtained by Chong differ dramatically from those based on 0lsson's measurements. The density obtained by Chong is 3.58 higher, Poisson's ratio is higher by a factor of 2.4 and Young's modulus in the vertical direction is higher by a factor of 2.5 . The most reasonable explanation would be that the two data sets do not represent the same material. This site appears inhomogeneous, so it is possible that the sandstone properties could vary dramatically over the site. In order to evaluate this conjecture, consider the positions from which the samples in these two data sets were obtained.

Figure 5 (from [16]) is an isopach map of the top of the sandstone at the Straight Creek Mine experiment site and shows the position of the exploratory holes. Eight of the nine samples for which Chong measured density and porosity are from Expl-4 at depths from $3.0 \mathrm{~m}$ to $6.0 \mathrm{~m}$, with the other sample coming from Expl-5 at a depth of $7.6 \mathrm{~m}$. Of the ten samples for which $p$-wave and $s$-wave velocities were measured, five are from Expl-4 at depths from 3.0m to $6.0 \mathrm{~m}$, two are from Expl-5 at a depth of $7.6 \mathrm{~m}$ and two are from Expl-2 at depths of $4.0 \mathrm{~m}$ and $4.3 \mathrm{~m}$. The remaining sample is repurted to be from Expl-2 at a depth of $8.2 \mathrm{~m}$. On the basis of the record of core sent to KPC \& Associates, this sample is 


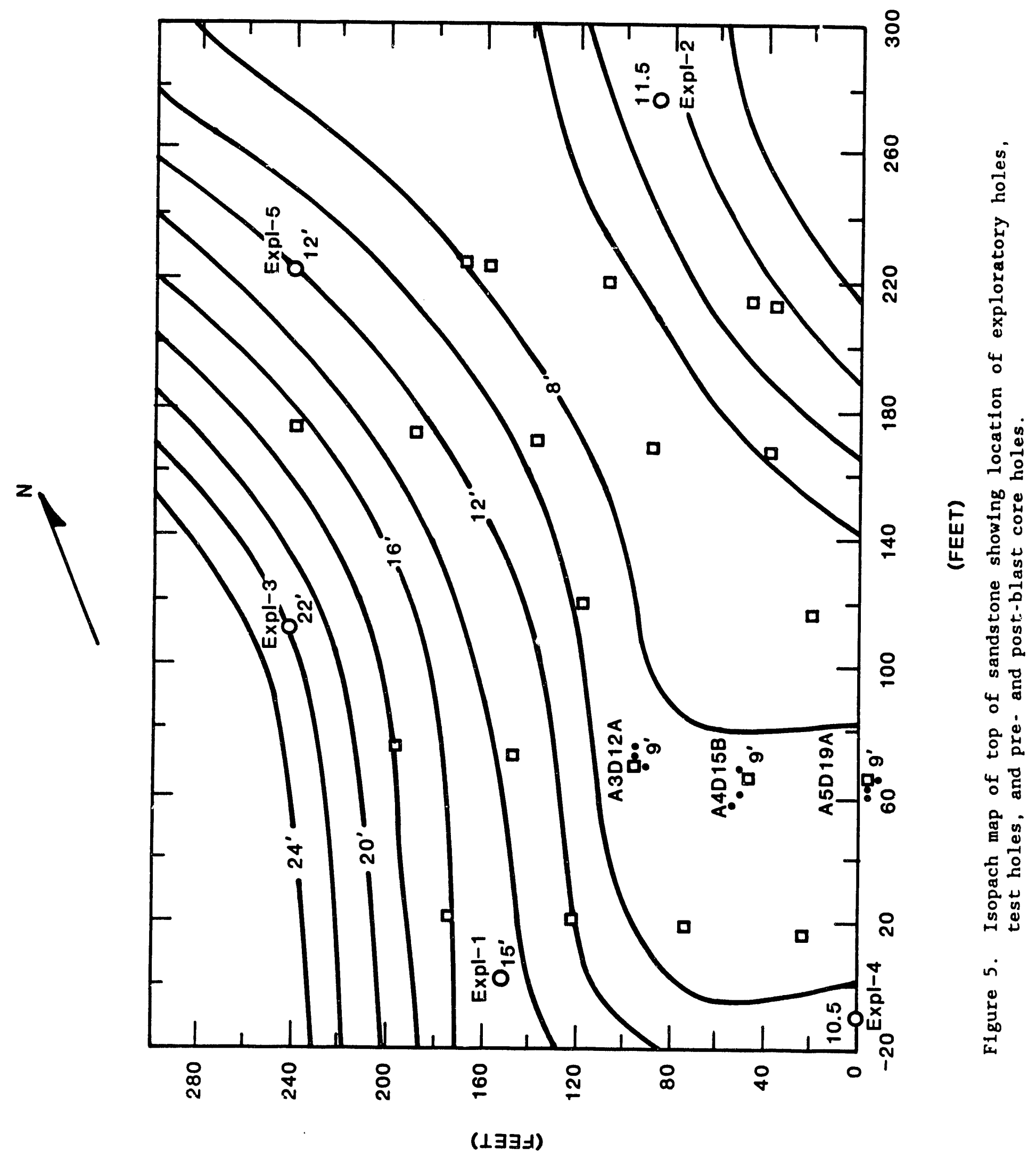


probably form Exp1-1 at the 8.2m depth. Of the nine samples used by 0lsson, eight are from Expl-1 at depths from 5.1m to $6.1 \mathrm{~m}$ and one is from Expl-2 at a depth between $4.3 \mathrm{~m}$ and $4.4 \mathrm{~m}$. This last sample is from a position only a few millimeters below Chong's sample from Expl-2 at a depth of $4.3 \mathrm{~m}$, and should represent the same material unless these two samples just happen to come from opposite sides of a major bedding plane. 0lsson's sample gives a vertical p-wave velocity of $2,770 \mathrm{~m} / \mathrm{s}$ while Chong obtained a $p$-wave velocity of $4,162 \mathrm{~m} / \mathrm{s}$. This difference is typical of the differences between the two data sets. Further, both data sets are self-consistent in spite of the fact that they both contain samples from opposite sides of the test site at various depths.

It seems reasonable to assume that the different material properties derived from the two sets of measurements are the result of systemacic differences in sample preparation or measurement procedures rather than real differences in the material in the samples. This leaves open the question of which set of material properties, if either, should be considered correct. Clearly, we must rely on Chong's data for $K$ and 0lsson's data for constructing the yield surface. Parameter variation studies were conducted to determine the sensitivity of calculated damage to variations in the other material properties over the rather large range of possible values implied by the differences in these two data sets.

\section{Sandstone Sensitivity Calculations}

In order to understand the sensitivity of calculated damage to differences in material properties over the range of variation implied by these two data sets, a large number of cratering calculations were carried out in which a homogeneous sandstone was assumed. The finite element configurations used were the same as those used in the Pamona Quarry crater calculations [9], except that the radii of the elements along the axis of symmetry were reduced to $66.5 \mathrm{~mm}$ to agree with the smaller 5.25 in diameter drill used at the Straight Creek Mine experiment site. Figure 6 shows a portion of the finite element configuration used to simulate a $3 \mathrm{~m}$ depth-of-burial to the center of the explosive charge. The radial dimension of the elements was gradually increased with radius, requiring 101 elements between the axis of symmetry and a nonreflecting boundary at a radius of $15 \mathrm{~m}$. A vertical dimension of $62.7 \mathrm{~mm}$ was used for elements between the bottom of the borehole at a depth of $3.5 \mathrm{~m}$ and the free boundary at the surface. The vertical dimension of the elements below the borehole was gradually increased with depth. There are 101 elements between the surface and a nonreflecting boundary at a depth of $20 \mathrm{~m}$, for a total of 10,201 elements. The explosives charge was modeled by the 16 elements blacked out in figure 6 between the $2.5 \mathrm{~m}$ and $3.5 \mathrm{~m}$ depths. Sensitivity calculations at depths to the center of the explosives charge of $2 \mathrm{~m}$ and $4 \mathrm{~m}$ were also performed, but these will not be discussed here. 


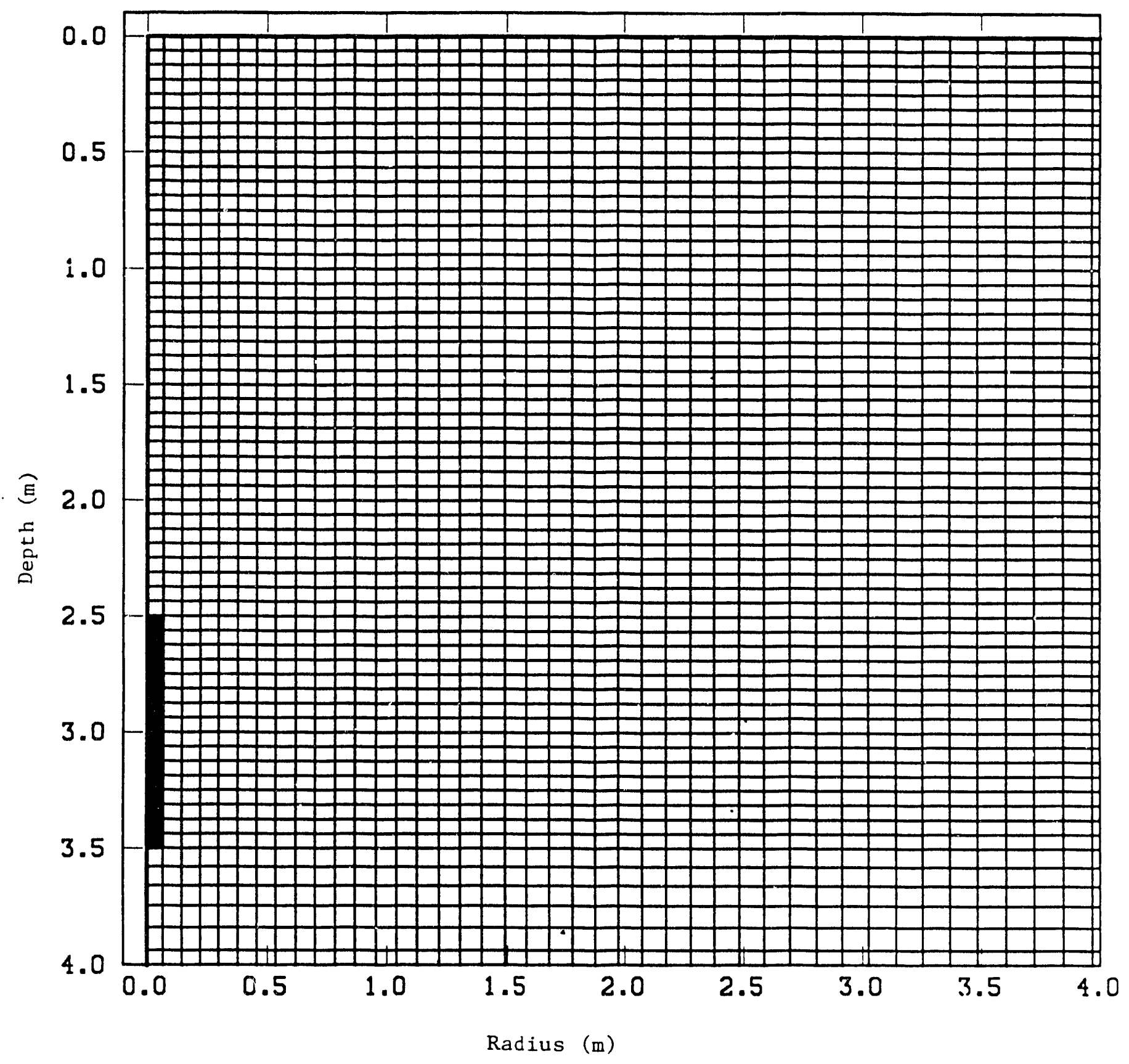

Figure 6. Finite element configuration used for $3 \mathrm{~m}$ depth-of-burial calculations. 
The explosive charge was modeled using the JWL equation-of-state subroutine [17] in the PRONTO 2D program [1]. Atlas Powder APEX 1220 and ANFO charges were simulated for each configuration. The APEX 1220 was modeled as having a $1250 \mathrm{~kg} / \mathrm{m}^{3}$ density, a $6065 \mathrm{~m} / \mathrm{s}$ detonation velocity and a $2.6 \times 10^{9} \mathrm{~J} / \mathrm{m}^{3}$ energy density. The ANFO was modeled as having a density of $810 \mathrm{~kg} / \mathrm{m}^{3}$, a detonation velocity of $3780 \mathrm{~m} / \mathrm{s}$ and an energy density of $6.91 \times 10^{8} \mathrm{~J} / \mathrm{m}^{3}$. It should be pointed out that the behavior of ANFO is not ideal at this small diameter. The energy density used in the JWL equation-of-state is artificially high in order to obtain a JWL release isentrope consistent with 458 of the real energy being released before the $C J$ point and 558 released after the CJ point. The detonation velocities used agree with measurements made at the Straight Creek Mine experimert site $[18]$.

Three of the calculations using ANFO at the $3 \mathrm{~m}$ depth-of-burial will be presented to illustrate trends typical of these calculations. The first of these uses Chong's data for all possible parameters. This results in the the following input to the damage model:

$\begin{array}{lll}\begin{array}{c}\text { SANDSTONE (ChONg) } \\ \text { DENSITY }\end{array} & \rho & 2,680 \mathrm{~kg} / \mathrm{m}^{3} \\ \text { YOUNG'S MODULUS } & \mathrm{E} & 41.48 \mathrm{GPa} \\ \text { POISSON'S RATIO } & \nu & 0.296 \\ \text { FRACTURE TOUGHNESS } & \mathrm{K} & 707 \mathrm{KPa} / \mathrm{m} \\ \text { YIELD PARAMETERS } & \mathrm{CP1} & 50 \mathrm{MPa} \\ & \mathrm{Y} 1 & 274 \mathrm{MPa} \\ & \mathrm{CP} 2 & 100 \mathrm{MPa} \\ & \text { Y2 } & 400 \mathrm{MPa} \\ & \mathrm{CP3} & 200 \mathrm{MPa} \\ & \mathrm{Y3} & 594 \mathrm{MPa} \\ \text { RELOAD } & \beta & 0.0 \\ \text { RMIN } & \mathrm{R} & 20 / \mathrm{s}\end{array}$

Here, Olsson's data are used for the yield surface and the value of $R$ and RELOAD are the same values used for Pamona Quarry granite [9]. These last two parameters were also included in the sensitivity study, but no results will be presented here except to point out that the calculations were not sensitive to variations in these two parameters over reasonable ranges of values. The default value of $k$, which is computed from the other material parameters [9], was used for all calculations. No othervalues of $\mathrm{k}$ were included in the sensitivity study because no data were available which could be used to estimate how much variation from the default value is reasonable. Figure 7 gives the calculated edge of the fragmented region for this simulation. Since no experiments have been performed in a homogeneous sandstone, it cannot be claimed that this is known to be a reasonable result.

The second calculation presented uses 0lsson's data for density and Poisson's ratio. The Young's modulus is determined from Olsson's average 
horizontal p-wave velocity. This results in the following changes to the above input for the damage model:

$\begin{array}{lll}\text { SANDSTONE (Olsson, Horizontal) } \\ \text { DENSITY } & \rho & 2,589 \mathrm{~kg} / \mathrm{m}^{3} \\ \text { YOUNG'S MODULUS } & E & 28.9 \mathrm{GPa} \\ \text { POISSON'S RATIO } & \nu & 0.112\end{array}$

Figure 8 gives the calculated edge of the fragmented region for this calculation. This is a dramatic decrease in the extent of the calculated fragmented region as compared to figure 7. Calculations varying these three parameters individually indicate that the calculated fragmented region is most sensitive to variations in the Young's modulus, second to variations in the Poisson's ratio and least sensitive to variations in the density.

In order to approximate the effects of the orthotropic material properties implied by 0lsson's p-wave velocity measurements, the damage model was modified to reduce the vertical stress below that computed for the isotropic case. This is equivalent to using a vertical Young's modulus, $E_{v}$, smaller than the Young's modulus, $E_{B}$, used in the radial and circumferential directions. This is not a consistent orthotropic model, but does result in the proper horizontal and vertical $p$-wave velocities. The third calculation presented uses this modified version of the damage model to simulate a material with the same material properties as the second calculation presented except for the following orthotropic Young's moduli:

\section{SANDSTONE (Orthotropic)

HORIZONTAL YOUNG'S MODULUS $\mathrm{E}_{\mathrm{B}} 28.9 \mathrm{GPa}$ \\ VERTICAL YOUNG'S MODULUS $\mathrm{E}_{\mathrm{v}} 19.7 \mathrm{GPa}$}

The predicted fragmented region for this calculation, shown in figure 9, is dramatically reduced from the calculation presented in figure 8. The damage model parameters were all computed using $E_{B}$, so they were the same for both calculations. Thus, this reduction in calculated damage is entirely due to the differences between isotropic and orthotropic wave propagation. An isotropic calculation using a Young's modulus of $19.7 \mathrm{GPa}$ resulted in even less damage and predicted no fragmentation at the surface.

From these three examples, it is clear that damage calculations in a homogeneous sandstone are extremely sensitive to differences in material properties as large as the differences implied by these two data sets, or even to the differences between the horizontal and vertical directions in 01sson's data set. Even with the same material properties being used in the damage model, orthotropic wave propagation dramatically reduced the calculated fragmented region. 


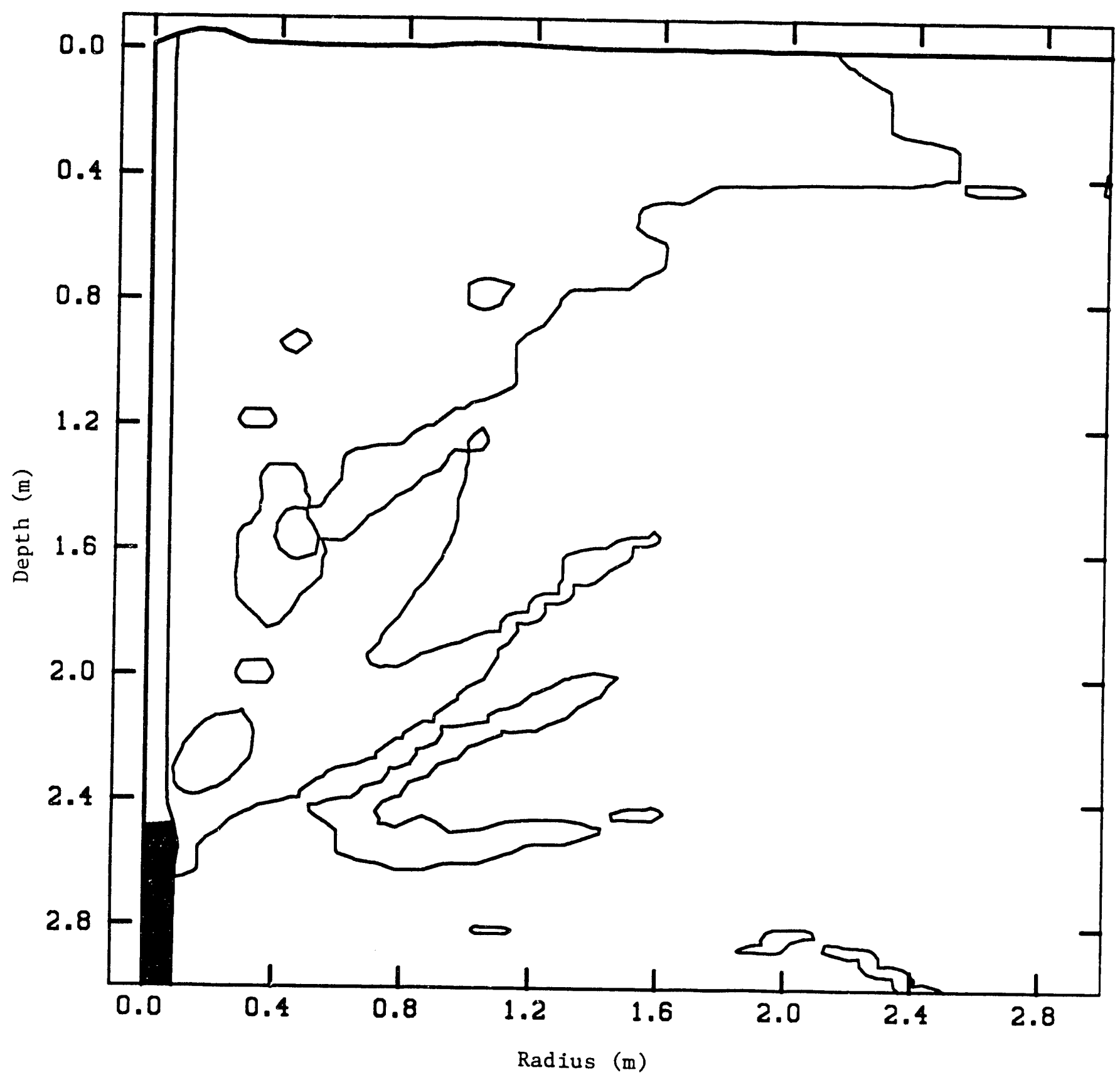

Figure 7. Calculated fragmented region for a $3 \mathrm{~m}$ depth-of-burial ANFO charge in a homogeneous isotropic sandstone using material properties measured by Chong et al. 


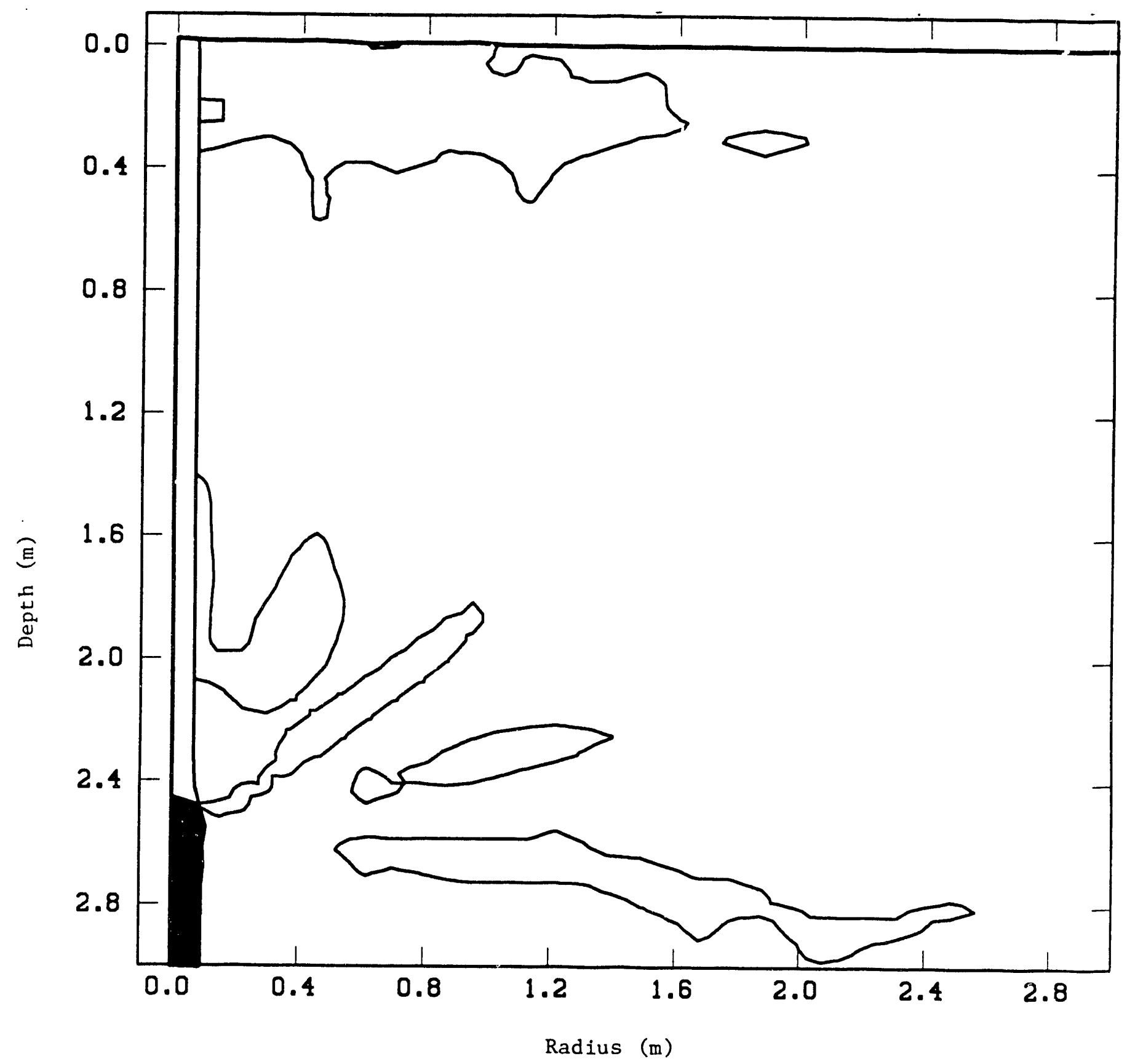

Figure 8. Calculated fragmented region for a $3 \mathrm{~m}$ depth-of-burial ANFO charge in a homogeneous isotropic sandstone using material properties based on horizontal p-wave velocities weasured by olsson. 


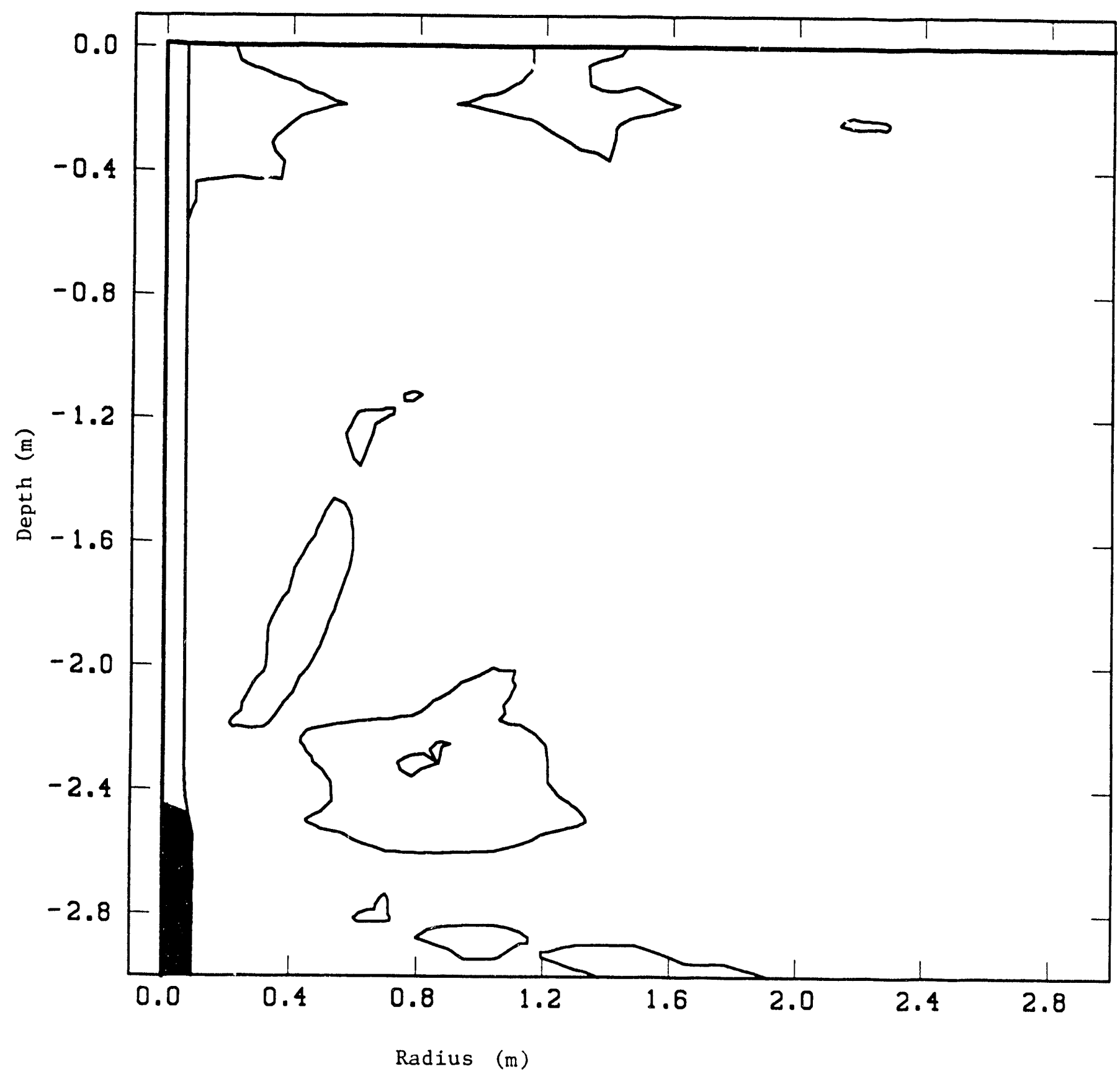

Figure 9. Calculated fragmented region for a $3 \mathrm{~m}$ depth-of-burial ANFO charge in a homogeneous orthotropic sandstone using material properties measured by 01 sson. 
None of the blast experiments at the Straight Creek Mine experiment site were in a homogeneous sandstone. Thus, the appropriate question for this test series is: How sensitive is cratering at the Straight Creek Mine experiment site to properties of the three materials at the site?

\section{Siltstone Material Properties}

Chong et al [12] report both $p$-wave and $s$-wave measurements in the vertical direction for ten siltstone samples from the Straight Creek Mine experiment site. For these samples, the average $p$-wave velocity was $3,600 \mathrm{~m} / \mathrm{s}$ with standard deviation $191 \mathrm{~m} / \mathrm{s}$, and the average $\mathrm{s}$-wave velocity was $1,739 \mathrm{~m} / \mathrm{s}$ with standard deviation $144 \mathrm{~m} / \mathrm{s}$. These velocities imply a Poisson's ratio of 0.342 with standard deviation 0.046 . Density and porosity were measured on eleven samples and resulted in an average density of $2,720 \mathrm{~kg} / \mathrm{m}^{3}$ with standard deviation $20 \mathrm{~kg} / \mathrm{m}^{3}$ and an average porosity of 3.828 with standard deviation 0.418 . This implies a solid material density of $2,828 \mathrm{~kg} / \mathrm{m}^{3}$. With the $2,720 \mathrm{~kg} / \mathrm{m}^{3}$ average density, the ten $p$-wave and $s$-wave velocity pairs imply an average Young's modulus of $21.96 \mathrm{GPa}$ with standard deviation 2.89GPa. Twelve semi-circular bend specimens gave an average $K$ in the horizontal direction of $622 \mathrm{KPa} / \mathrm{m}$ with standard deviation $48 \mathrm{KPa} / \mathrm{m}$, and five chevron bend specimens gave an average $\mathrm{K}$ in the vertical direction of $332 \mathrm{KPa} / \mathrm{m}$ with standard deviation $80 \mathrm{KPa} / \mathrm{m}$. This indicates an anisotropy, which is consistent with the layered appearance of this material. Since $p$-wave and $s$-wave velocities were not measured in the horizontal direction, it is not known how this anisotropy might effect the elastic constants.

In terms of the material properties needed for input to the damage model, this data set can be summarized as follows:

\section{SILTSTONE \\ DENSITY \\ $\quad \rho-2,720 \mathrm{~kg} / \mathrm{m}^{3}$ \\ E $21.96 \mathrm{MPa}$ (Vertical) \\ $\begin{array}{llll}\text { POISSON'S RATIO } & \nu & 0.342 & \\ \text { FRACTURE TOUGHNESS } & \mathrm{K} & 622 \mathrm{KPa} / \mathrm{m} \quad \text { (Horizontal) }\end{array}$ \\ $\begin{array}{llll}\text { FRACTURE TOUGHNESS } \mathrm{K} \quad \begin{array}{l}622 \mathrm{KPa} / \mathrm{m} \\ 332 \mathrm{KPa} / \mathrm{m}\end{array} & \begin{array}{l}\text { (Horizontal) } \\ \text { (Vertical) }\end{array}\end{array}$}

\section{Mudstone Material Properties}

Chong et al [12] report both $p$-wave and $s$-wave measurements in the vertical direction for ten mudstone samples from the Straight Creek Mine experiment site. For these samples, the average $p$-wave velocity was $3,136 \mathrm{~m} / \mathrm{s}$ with standard deviation $488 \mathrm{~m} / \mathrm{s}$, and the average $\mathrm{s}$-wave velocity was $1,082 \mathrm{~m} / \mathrm{s}$ with standard deviation $108 \mathrm{~m} / \mathrm{s}$. These velocities imply a Poisson's ratio of 0.428 with standard deviation 0.020 . Density and porosity were measured on nine samples and rsulted in an average density of $2,690 \mathrm{~kg} / \mathrm{m}^{3}$ with standard deviation $80 \mathrm{~kg} / \mathrm{m}^{3}$ and an average porosity of 5.988 with standard deviation 0.618 . This implies a solid material density of $2,861 \mathrm{~kg} / \mathrm{m}^{3}$. With the $2,690 \mathrm{~kg} / \mathrm{m}^{3}$ average density, the ten $p$-wave and $s$-wave velocity pairs imply an average Young's modulus of $9.07 \mathrm{GPa}$ with standard deviation $1.77 \mathrm{GPa}$. Sixteen semi-circular 
bendspecimens gave an average $K$ in the horizontal direction of $374 \mathrm{KPa} / \mathrm{m}$ with standard deviation $44 \mathrm{KPa} / \mathrm{m}$. All attempts to measure $\mathrm{K}$ in the vertical direction by use of cheiron bend specimens resulted in separation at layer interfaces before a crack could develof, at the notch tip [12]. This is a thinly layered material with vary weak cohesion between layers.

In terms of the material properties needed for input to tine damage model, this data set can be summarized as follors:

MUDSTONE

$\begin{array}{llll}\text { DENSITY } & \rho & 2,690 \mathrm{~kg} / \mathrm{m}^{3} & \\ \text { YOUNG'S MODULUS } & \mathrm{E} & 9.07 \mathrm{GPa} & \text { (Vertica]) } \\ \text { POISSON'S RATIO } & \nu & 0.428 & \\ \text { FRACTURE TOUGHNESS } & \mathrm{K} & 374 \mathrm{KPa} / \mathrm{m} & \text { (Horizontal) }\end{array}$

Straight Creek Experiment Site Stracigraphy

While it would be possible to perform sensitivity studies unrelated to the blast experiments, it seems prudent to concentrate efforts on situations of experimental significance. A pre-blast core and two postblast cores were taken adjacent to the three-blast experiment boreholes designated as $A 3 D 12 A, A 4 D 15 B$ and $A 5 D 19 A$ in figure 5. No natural fractures were detected in any of the pre-blast cores [16]. This allows the post-blast cores to be used to estimate the extent of fracturing from these blasting experiments. Of these three blast experiments, only A3D12A resulted in a crater. Sensitivity studies were concentrated on, but not limited to, modeling of this blast experiment.

Figure 10 (from (16]) is a schematic diagram of the lithography near the A3D12A blast experiment borehole. It shows the approximate excavated crater profile, the distance of the post-blast core holes from the blast experiment borehole, a generalized stratigraphy and the location of blast induced fractures. The blast experiment borehole is assumed to have the same lithology as the pre-blast core. Notes on lost circulation during the coring operation are also included in figure 10 . In the segments where no core was recovered, the driller reported that the core bit was pushing rather than cutting the rock, suggesting that the rock was rubblized and that there was available volume into which the rock could be pushed [16].

Figure 11 shows the p.sition of the explosive charge and the position of the material interfaces in the finite element approximation to the A3D12A blast experiment. Note that the top of the explosive charge extends $270 \mathrm{~mm}$ into the siltstone. It had been planned to position the top of the explosive charge at the interface between the sandstone and the siltstone, as shown in figure 10, but measurements taiken during preparation of the blast experiment imply that the geometry shown in figure 11 is more accurate [18]. The position of the post-blast core holes are indicated by the vertical lines $0.4 \mathrm{~m}$ and $1.0 \mathrm{~m}$ from the center line of the blast experiment borehole. The size and number of elements used was as near as possible to the same as was used for the sandstone material property sensitivity studies (figure 6 ). 


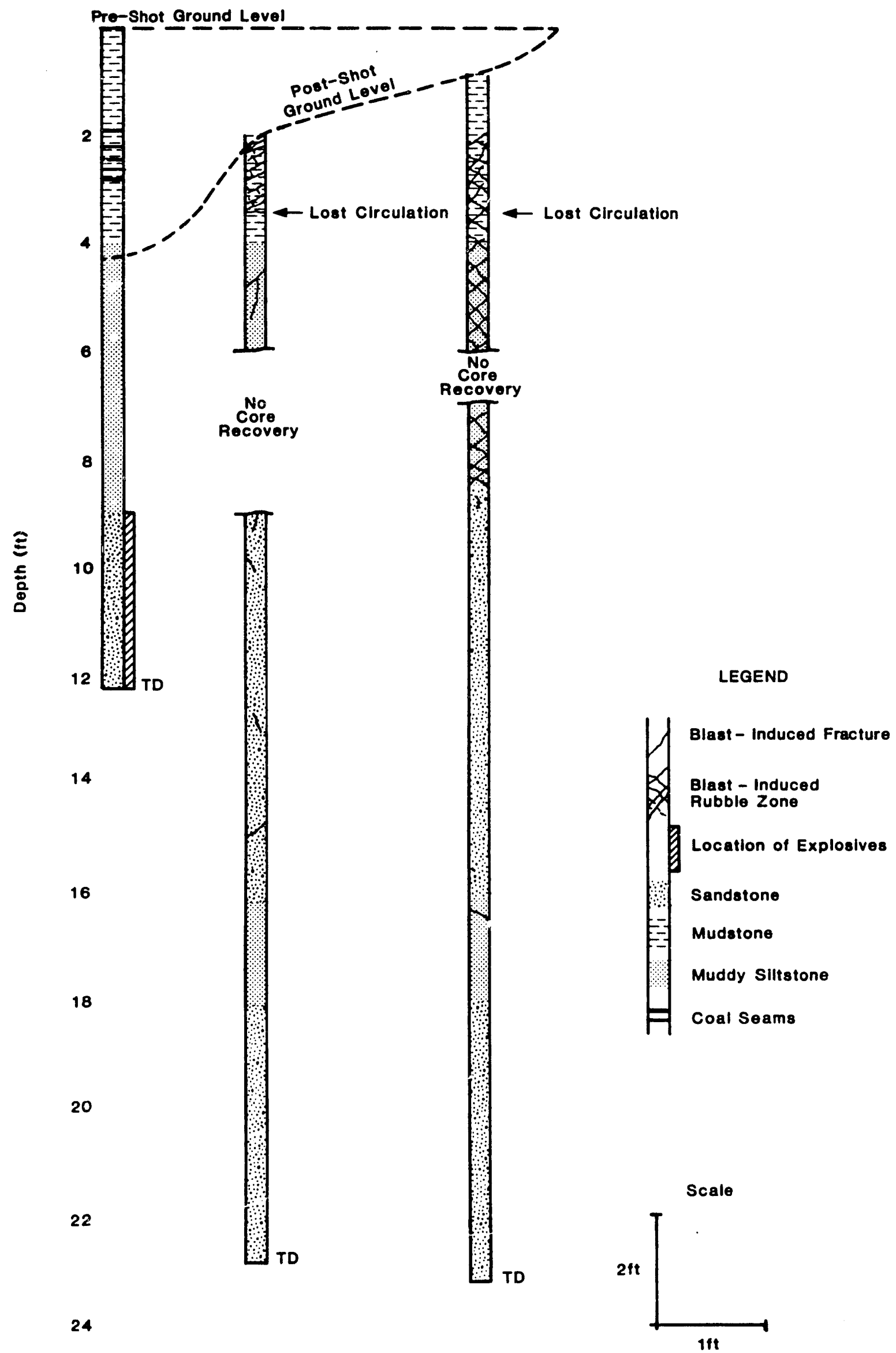

Figure 10. Schematic diagram of the 11thography near the A3D12A blast experiment borehole. 


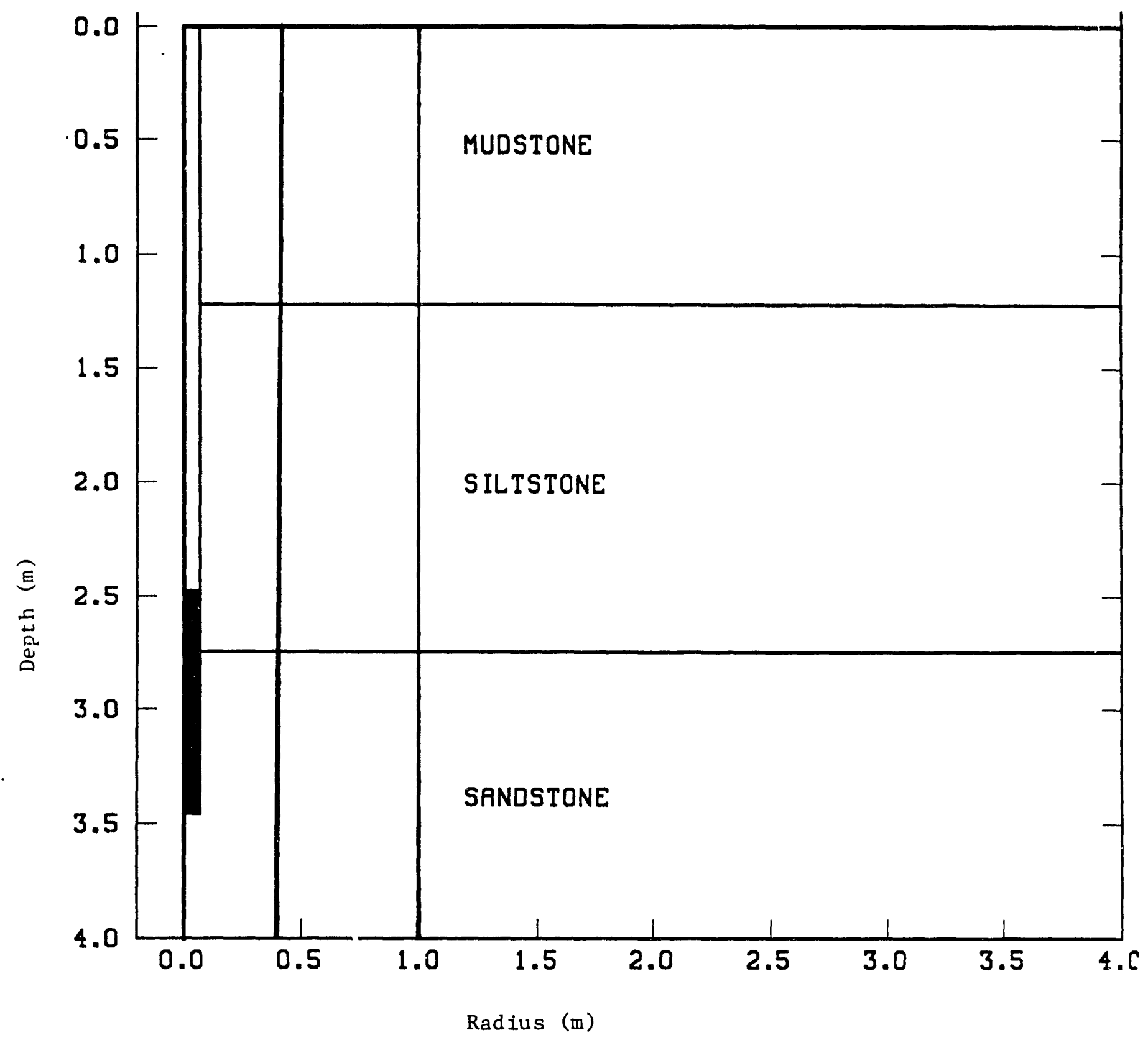

Figure 11. Position of explosive charge and material interfaces in the finite element approximation to the A3D12A blast experiment. 


\section{Site-Specific Sensitivity Calculations}

In addition to uncertainties in the sandstone properties, there is considerable uncertainty about the proper material properties to use in modeling the siltstone and mudstone. For the siltstone, $K$ varies by a factor of almost two between the horizontal and vertical directions. For the mudstone the uncertainty in $K$ is even greater, as it was impossible to measure $K$ in the vertical direction. Since the $K$ values measured in the horizontal direction represent the maximum possible strength of both materials, the calculations presented here use these values and give a lower bound on the amount of calculated damage as compared with several calculations using smaller values of $\mathrm{K}$.

No triaxial tests were performed on siltstone or mudstone samples. Thus, no data on which to base a yield surface for these materials were available. Since the top of the explosive charge extended into the siltstone for the A3D12A blast experiment, the yield surface assumed for the siltstone could possibly have a significant effect on calculated damage. The calculations presented here assume that the yield surfaces of the siltstone and mudstone are the same as used for the sandstone. It was also assumed that the values of both $R$ and RELOAD used in the sandstone could be used for both the siltstone and the mudstone. The default value was used for $k$ in all calculations.

\section{(1) Material Properties}

It would be very difficult to present the results of all of the calculations involved in this sensitivity study. Instead, a few of these calculations will be presented to illustrate trends. The first three calculations presented address the issue of sensitivity to properties of the sandstone. The above material properties for the siltstone and mudstone were used in these three calculations. Calculations were performed using each of the three sets of sandstone material properties discussed in the section on sensitivity to sandstone material properties.

Figure 12 shows the limit of the predicted fragmented region for the calculation using sandstone material properties based on Chong's data. The approximate profile of the excavated crater is indicated by the dashed line and the location of the post-blast core holes is indicated by the vertical lines. Figure 13 gives the corresponding results for a calculation using material properties for the sandstone based on 01sson's data and using a Young's modulus based horizontal p-wave velocity measurement. Figure 14 shows the results of using the orthotropic approximation based on 0lsson's data for sandstone. There are no significant differences in the extent of the fragmented region in these three calculations. This indicates that damage calculated in the Straight Creek Mine experiment site stratigraphy is not sensitive to variations in material properties of the sandstone within the range of values implied by the two available data sets. 


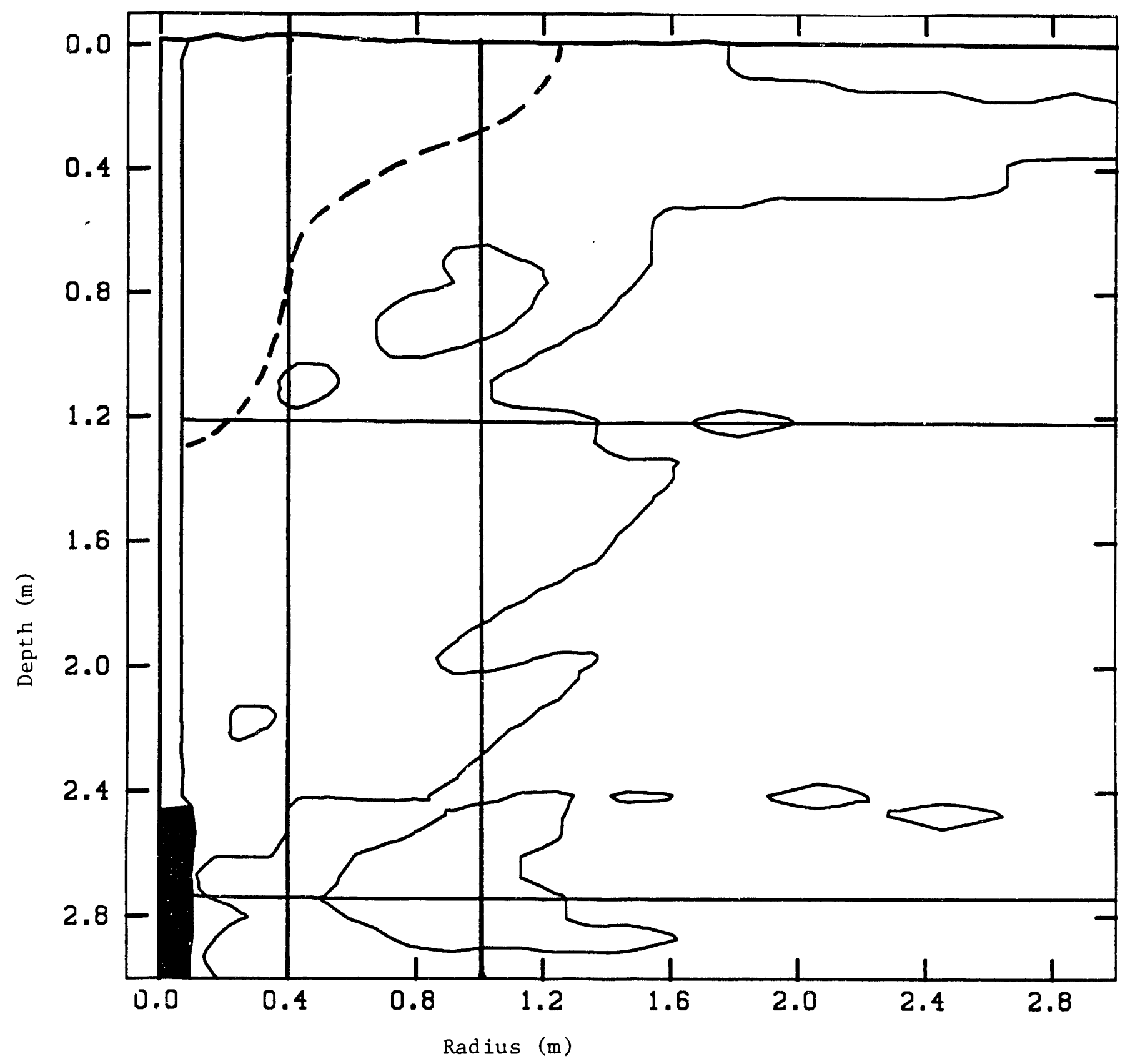

Figure 12. Calculated fragmented region for the A3D12A blast experinent using material. properties measured by Chong et al. 


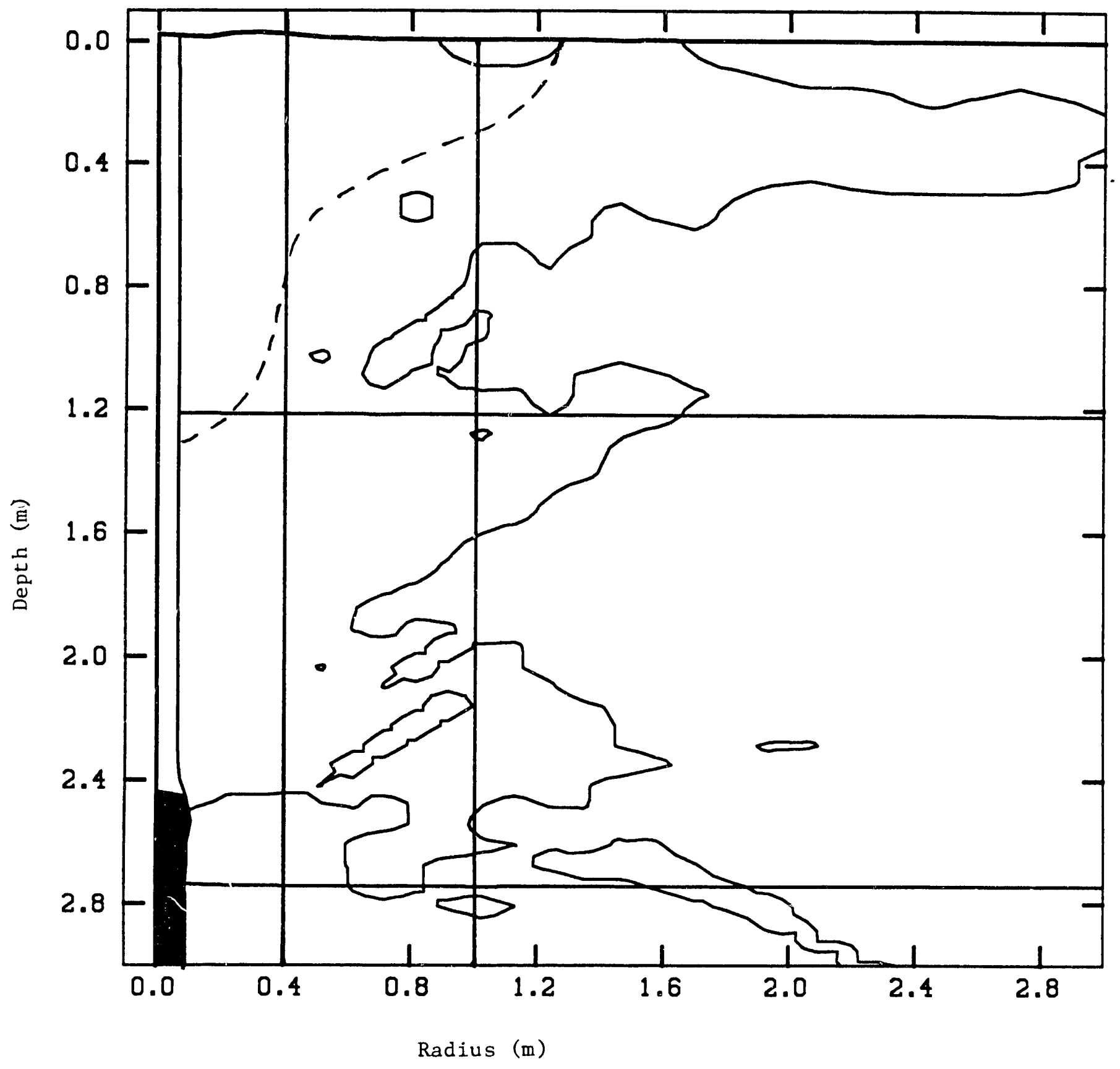

Figure 13. Calculated fragmented region for the A3D12A blast experiment using isotropic sandstone material properties based on horizontal p-wave velocities measured by oisson. 


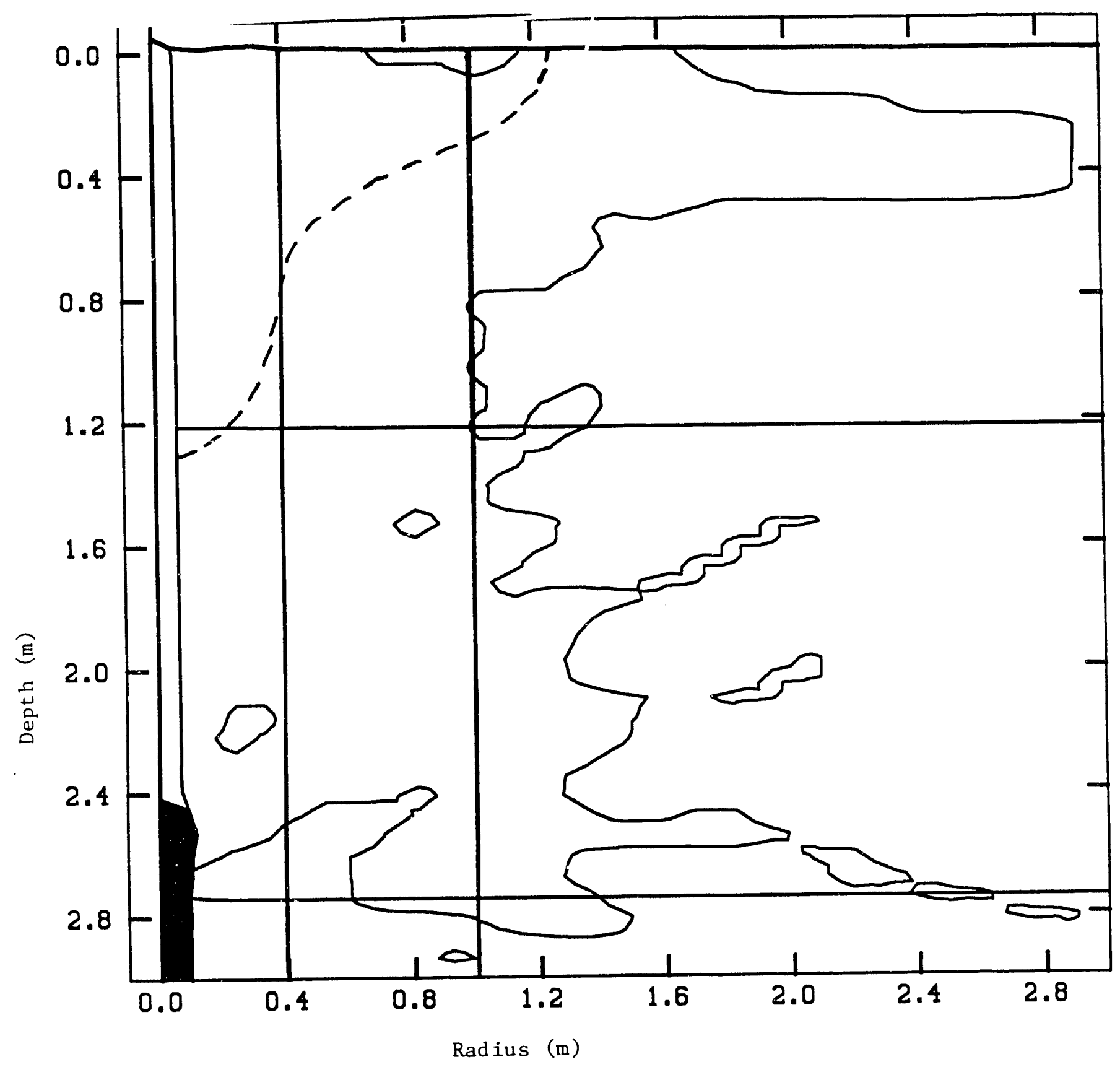

Figure 14. Calculated fragmented region for the A3D12A blast experiment using orthotropic sandstone material properties measured by olsson. 
Clearly, these calculations overestimate the extent of the fragmented region. Varlation of the material properties for the siltstone and mudstone over reasonable sets of values resulted in calculated fragmented regions comparable to or larger than those shown in figures 12 through 14. None of these calculations were found to be sensitive to the yield surface, the value of $R$ or the value of RELOAD assumed for any of the materials.

Certainly, the layered appearance of the siltstone and mudstone and the large anisotropy in $\mathrm{K}$ for both materials indicate that the elastic properties of these materials are likely to be at least as anisotropic as the sandstone. The most reasonable assumption would be that the $p$-wave velocity in the horizontal direction would be larger than the values measured for the vertical direction. A calculation was performed using the orthotropic approximation assuming that the difference between the horizontal and vertical Young's moduli for the siltstone and mudstone were in the same ratio as in olsson's data for the sandstone. This calculation resulted in a calculated fragmented region greatly exceeding those shown in figures 12 through 14, which are already much larger than indicated by the excavated crater and post-blast cores.

Figure 15 shows the predicted fragmented region for a calculation based on an interesting, but hard to justify, set of assumptions. Since the data sets of Chong and olsson resulted in different vertical $p$-wave velocities for the sandstone, it is reasonable to speculate that olsson might have obtained lower $p$-wave velocities for siltstone and mudstone if he had been asked to measure these values. In fact, if the differences in the sandstone $p$-wave velocities for the two daia sets are the result of some systematic difference in sample preparation, it might be reasonable to conjecture that $01 s s o n$ would have measured p-wave velocities for the siltstone and mudstone materials which would be lower by the same ratio as in the sandstone. If that ratio is calculated using olsson's vertical $p$-wave velocity, then the resulting Young's moduli for siltstone and mudstone would be $10.4 \mathrm{GPa}$ and $4.3 \mathrm{GPa}$, respectively. The calculation corresponding to figure 15 differs from the calculation corresponding to figure 13 only in the use of these values for the Young's moduli of the siltstone and mudstone. As would be expected, the reduced values of the Young's moduli used in these calculations reduce the amount of calculated damage in both the siltstone and mudstone. However, the size and shape of the fragmented region is still in poor agreement with the excavated crater and post-blast core.

\section{(2)}

Effects of Layering

In an attempt to estimate the effects of the thin coal seams shown in figure 10, three thin layers of elements using material properties for coal from another site were inserted into the finite element model at approximately the proper depth in the mudstone. The coal was modeled using the damage model with the following material properties: 


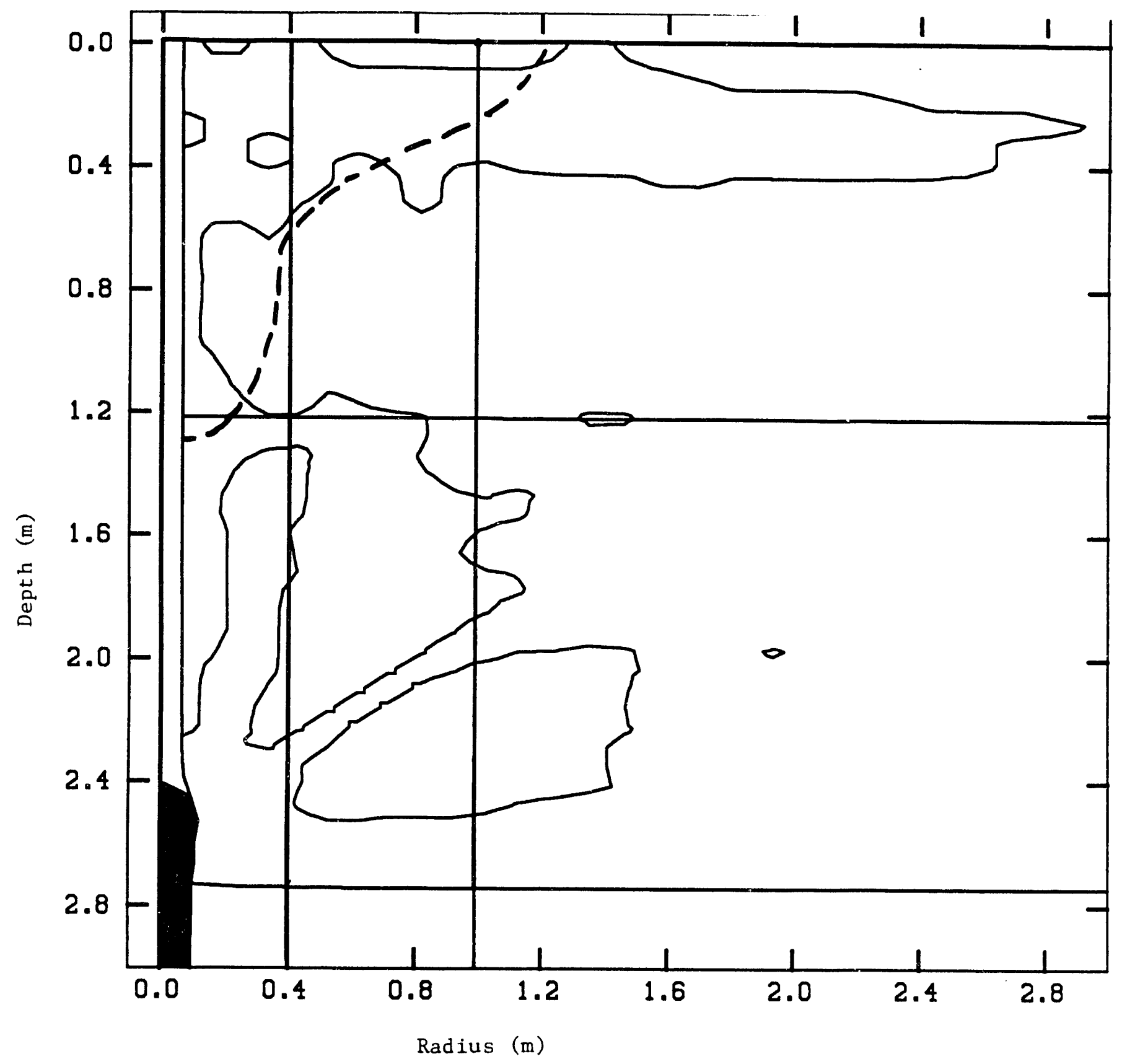

Figure 15. Calculated fragmented region for the A3D12A blast experiment using reduced Toung's moduli for siltstone and mudstone. 
COAL

$\begin{array}{lll}\text { DENSITY } & \rho & 1,600 \mathrm{~kg} / \mathrm{m}^{3} \\ \text { YOUNG'S MODULUS } & \mathrm{E} & 2.95 \mathrm{GPa} \\ \text { POISSON'S RATIO } & \nu & 0.39 \\ \text { FRACTURE TOUGHNESS } & \mathrm{K} & 50 \mathrm{KPa} / \mathrm{m}\end{array}$

All other damage model parameters for the coal seams were chosen to be the same as in the other three materials. Material properties for the sandstone were isotropic and based on 0lsson's data using the Young's modulus based on his horizontal p-wave velocities. The siltstone and mudstone material properties were based on Chong's data. Thus, this calculation differed from the one corresponding to figure 13 only in that the coal seams were included.

Figure 16 shows the location of the three thin coal seams and the limit of the fragmented region for this calculation. The excavated crater profile and the location of the post-blast core holes are also shown. Even though the coal is much weaker than the mudstone, including the thin coal seams in the model reduced the radius of the calculated fragmented region at and just above the depth of the coal seams. This may be because the weak coal seams inhibit the propagation of tensile waves by breaking easily.

It seems possible that delamination of the thin layers in the mudstone could have a similar effect. As a test of this hypothesis, three thin layers of elements were inserted into the mudstone above the coal seams. These three layers were given the same material properties as the mudstone, except that the value of $\mathrm{K}$ was taken to be $10 \mathrm{KPa} / \mathrm{m}$ to simulate vexy weak delamination zones. Figure 17 shows the location of these three thin layers of weak elements above the three thin coal seams, and also the excavated crater profile and the location of the post-blast core holes. The radius of the limit of the predicted fragmented region for this calculation, also shown in figure 17, is significantly reduced in the region above the coal seams as compared to figure 16.

While three thin seams of weak material cannot be claimed to be a good approximation to delamination along hundreds of closely spaced bedding planes, the reduction of calculated damage in the mudstone using this simple approximation indicates that ignoring the anisotropic nature of the fracture strength in the mudstone is probably one source of the excessive calculated damage shown in figure 13. Even though the largest experimentally justifiable value of $K$ was used in the isotropic finite element model, the amount of calculated damage was reduced by including thin seams of materials with very low values of $K$ resulting in reduced tensile wave propagation in the vertical direction. This same effect would be expected to apply, possibly to a lesser extent, to the siltstone where the value of $K$ for the vertical direction was a little more than half of the value for the horizontal direction. 


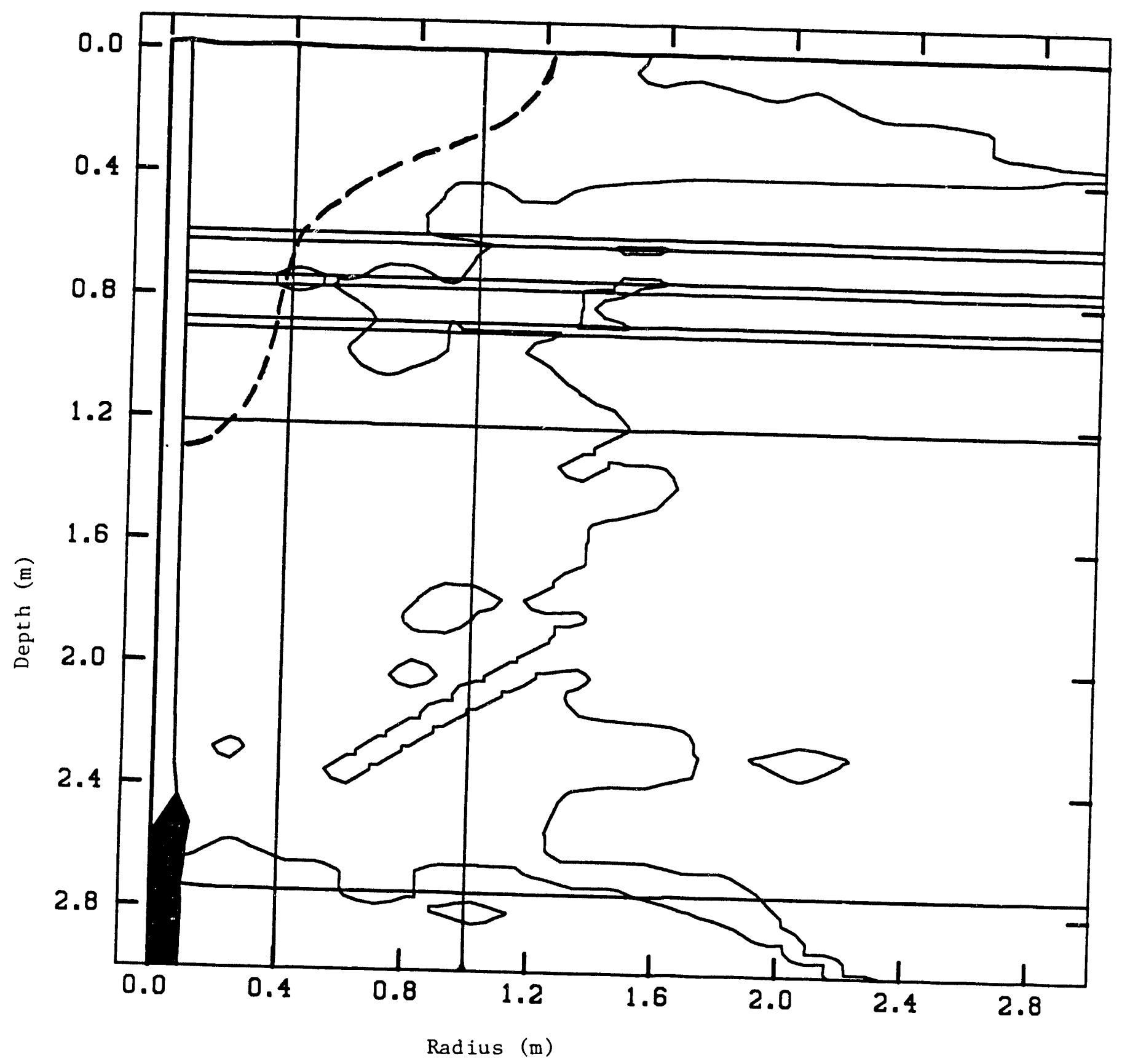

Figure 16. Calculated fragmented region for the A3D12A blast experiment 


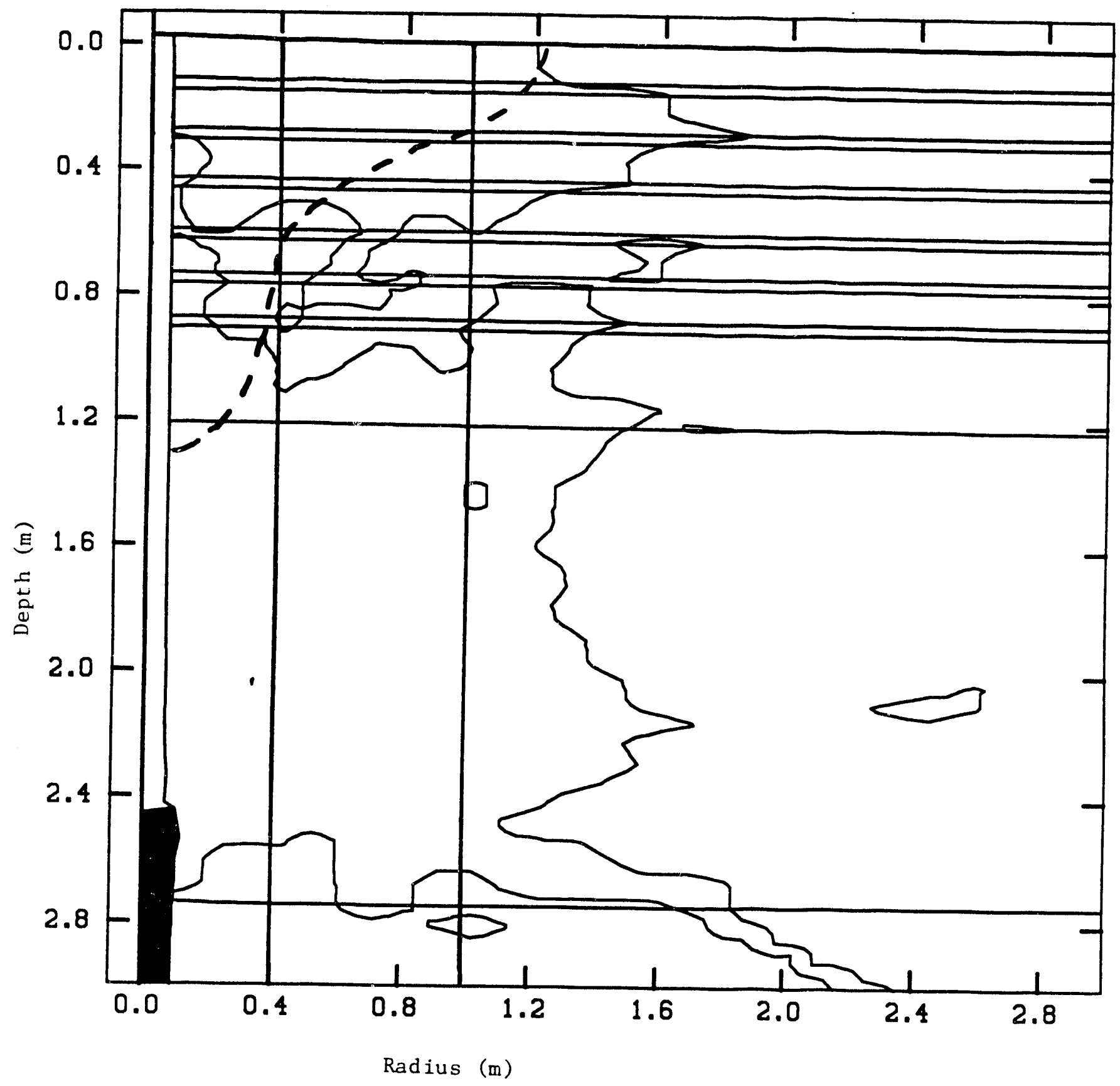

Figure 17. Calculated fragmented region for the A3D12A blast experiment including three thin coal seams and three thin weak seams. 


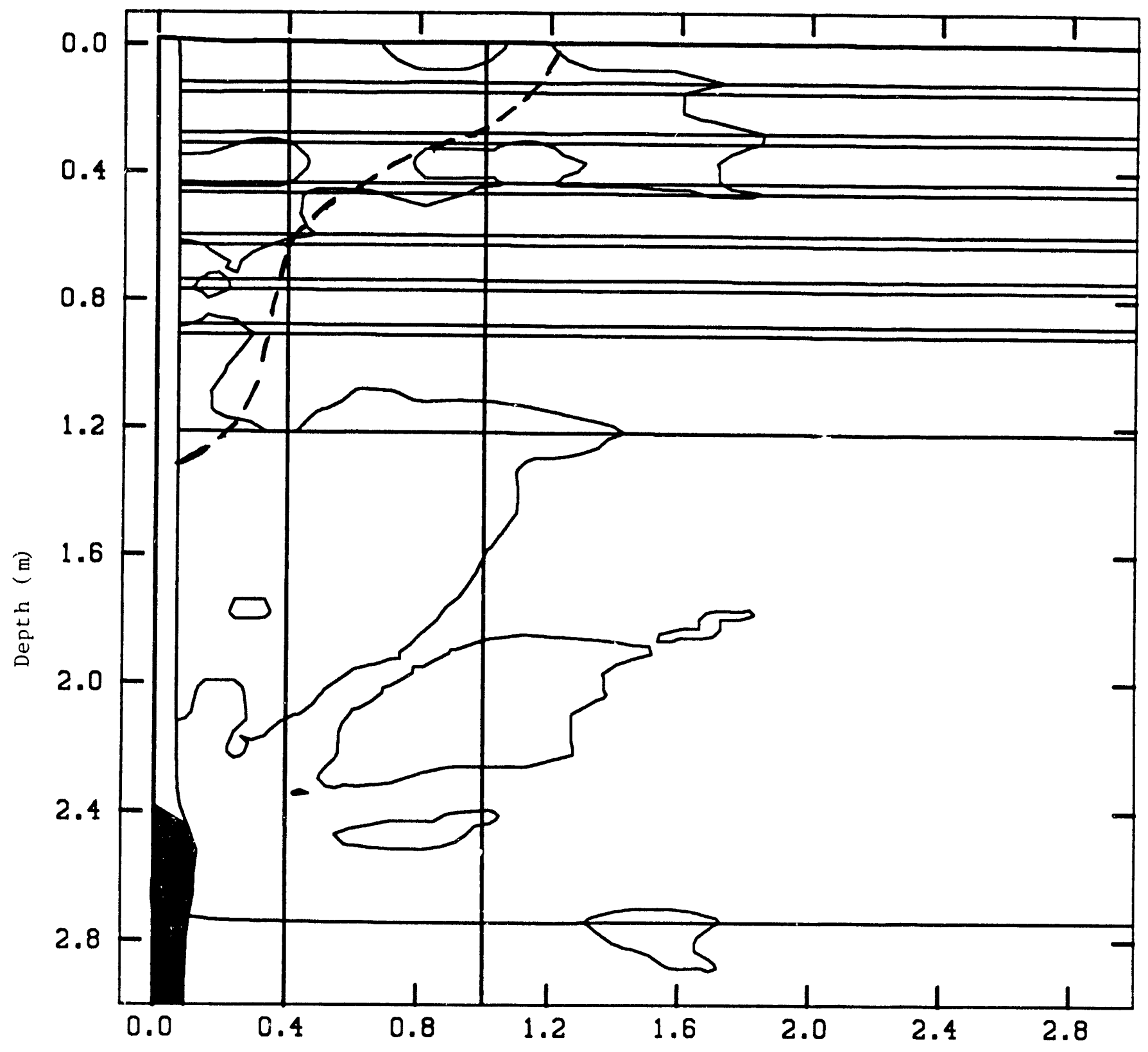

Radius (m)

Figure 18. Calculated fragmented region for the A3D12A blast experiment including three thin coal seams, three thin weak seams and using reduced Young's moduli for the siltstone and mudstone. 
A final calculation is shown in figure 18, where the predicted fragmented region is shown for a calculation including both the three coal seams and the three thin weak seams, as in the calculation corresponding to figure 17, and using the reduced values for Young's moduli from the calculation shown in figure 15. In this calculation the predicted fragmented region is in reasonable agreement with the excavated crater profile. The calculated fragmented region below the crater might also be considered to be in roughly the same position as the region for which no core was recovered. However, it would be hard to justify considering the rough agreement between this calculation and the field data to be a validation of the damage model, especially when the amount of speculation involved is considered. 


\section{CONCLUSIONS}

Comparison of calculations with blast experiments in granite at the Pamona Quarry [\%] indicated that reasonable results could be obtained with an isotropic damage model, even using average material properties for a significantly anisotropic material. However, application of the current version of this damage model to analysis of the Straight Creek Mine blast experiments indicates that anisotropy cannot be ignored. Comparison wich experiments in a wide variety of isotropic rocks must be carried out before it will be known whether or not the current version of the model is a useful engineering tool in isotropic materials. More precisely controlled experiments are likely to indicate areas where the current version of the damije model can be improved. Even for isotropic materials, a tensor damage measure based on the entire strain tensor is probably needed to adequately model the accumulation of damage and the effects of damage on material response.

The current damage model allows numerically stable calculations even when large amounts of damage are predicted. These calculations can be carried out in as litile as one percent of the computer time required for calculations with older versions of the damage model. This increased speed has allowed efficient parameter variation studies to evaluate the effects of variation in material properties over the considerable range of uncertainty indicated by laboratory data for the Straight Creek Mine experiment site. As would be expected from the equations [9], the armage calculated is very sensitive to the ratio of the Young's modulus of the material to the fracture toughness of the material, $E / K$. In fact, the range of uncertainty for the Young's modulus of the sandstone at the Straight Creek experiment site results in a range of calculated damage varying from a large fragmented region intersecting the surface when the maximum value is used to no fragmentation at the surface when the minimum value is used.

Anisotropic wave propagation effects the damage predicted even when compared to isotropic wave propagation using the same material properties for calculation of the damage model parameters. In addition, anisotropic fxacture toughness may effect the material response in a complex way, as indicated by the fact that less damage was calculated when thin layers of a very weak material were included in the finite element model for the mudstone at the Straight Creek Mine experiment site. A consistent model for anisotropic wave propagation and a damage model for anisotropic materials are both necessary for damage prediction at layered sites similar to the Straight Creek Mine experiment site. 


\section{ACKNOWLEDGEMENTS}

The author would like to express his thanks to D. S. Preece, B. H. Schrandt and P. M. Drozda for help with the blast experiment data and to D. S. Preece, E. P. Chen, D. J. Holcomb, M. E. Kipp and D. E. Grady for fruitful discussions of the theory behind the damage model. 


\section{REFERENCES}

[1] Taylor, L. M. and Flanagan, D. P., "PRONTO 2D A Two-Dimensional Transient Solid Dynamics Program," SAND86-0594, Sandia National Laboratories, Albuquerque NM, March 1987.

[2] Taylor, L. M. and Flanagan, D. P., "PRONTO 3D A Three-Dimensional Transient Solid Dynamics Program," SAND87-1912, Sandia National Laboratories, Albuquerque NM, March 1989.

[3] Taylor, L. M. and Preece, D. S., "DMC-A Rigid Body Motion Code for Determining the Interaction of Multiple Spherical Particles," SAND88-3482, Sandia National Laboratories, Albuquerque NM, July 1989 .

[4] Preece, D. S. and Taylor, L. M., "Spherical Element Bulking Mechanisms for Modelifing Blast Induced Rock Motion," Third International Symposium on Rock Fragmentation by Blasting, Brisbane, Queensland, Australia, August 1990.

[5] Kipp, M. E. and Grady, D. E., "Numerical Studies of Rock Fragmentation," SAND79-1582, Sandia National Laboratories, Albuquerque NM, 1980.

[6] Taylor, L. M., Chen, E. P. and Kuszmaul, J. S., "Microcrack-Induced Damage Accumulation in Brittle Rock Under Dynamic Loading, " Computer Methods in Applied Mechanics and Engineering, vol. 55, no.3, Pp. 301-320, 1986.

[7] Kuszmaul, J. S., "A New Constitutive Model for Fragmentation of Rock Under Dynamic Loading," in Proceedings of the Second International Symposium on Fragmentation by Blasting, Keystone CO, Pp 412-423, August 1987.

[8] Thorne, B. J., Hommert, P. J. and Brown, B., "Experimental and Computational Investigation of the Fundamental Mechanisms of Cratering," Third International Symposium on Rock Fragmentation by Blasting, Brisbane, Queensland, Australia, August 1990.

[9] Thorne, B. J., "A Damage Model for Rock Fragmentation and Comparison of Calculations with Blasting Experiments in Granite," SAND90-1389, Sandia National Laboratories, Albuquerque NM, October 1990.

[10] Chong, K. P., Basham, K. D., Wang, D. Q. and Estes, R. J., "Fracture Toughness Characterization of Eastern Basalt and Gneiss, "KPC \& Associates report to Sandia National Laboratories on contract No. 55-5698, Laramie WY, June 1988.

[11] 0lsson, W. A., "Quasi-Static and Dynamic Mechanical Properties of a Granite and a Sandstone," SAND89-1197, Sandia National Laboratories, Albuquerque NM, September 1989. 
[12] Chong, K. P., Basham, K. D., Chong, F. T., Estes, R. J. and Wang, D. Q., "Mechanical Properties of Sandstone, Siltstone and Mudstone," KPC \& Associates report to Sandia National Laboratories on contract No. 75-270, Laramie WY, January 1989.

[13] D. J. Holcomb, "Memory. Relaxation and Microfracturing in Dilatant Rock", Journal of Geophysical Research, Vol. 86 pp 6235-6248, July 1981

[14] D. J. Holcomb and L. S. Costin, "Detecting Damage Surfaces in Brittle Materials Using Acoustic Emissions" Journal of Applied Mechanics, Vol. 108, September 1986

[15] Costin, L. S. and Stone, M., "A Finite Element Material Model for Microfracture-Damaged Brittle Rock," SAND87-1227, Sandia National Laboratories, Albuquerque NM, June 1987.

[16] Finley, S. J., "Blast-Induced Fracturing in Core From the Straight Creek Mine Experiment Site," Memo to Dale Preece, Sandia National Laboratories, Division 6258, December 14, 1988.

[17] Dobratz, B. M., "LLNL Explosives Handbook - Properties of Chemical Explosives and Explosive Stimulants," DE85-015961 Lawrence Livermore National Laboratory, Livermore CA, March 1981.

[18] Schrandt, B. H., Preece, D. S. and Thorne, B. J., "Computer Analysis of Straight Creek Mine Experiment Survey Data," Proprietary Sandia Report, SAND90-2157, Sandia National Laboratories, Albuquerque NM, November 1990. 


\section{APPENDIX A \\ PRONTO CHANGes TO IMPLEMENT THE NEW DAMAGE MODEL}

The only difference between the FORTRAN shown here and that included in PRONTO 2D version 4.5.6 is that in the FORTRAN below the intersection of the yield surface and the uniaxial test conditions line is calculated and the corresponding pressure is passed as PROP(11). In subroutine MATINT at step 12 substitute the following FORTRAN for the old material model 15 initiation:

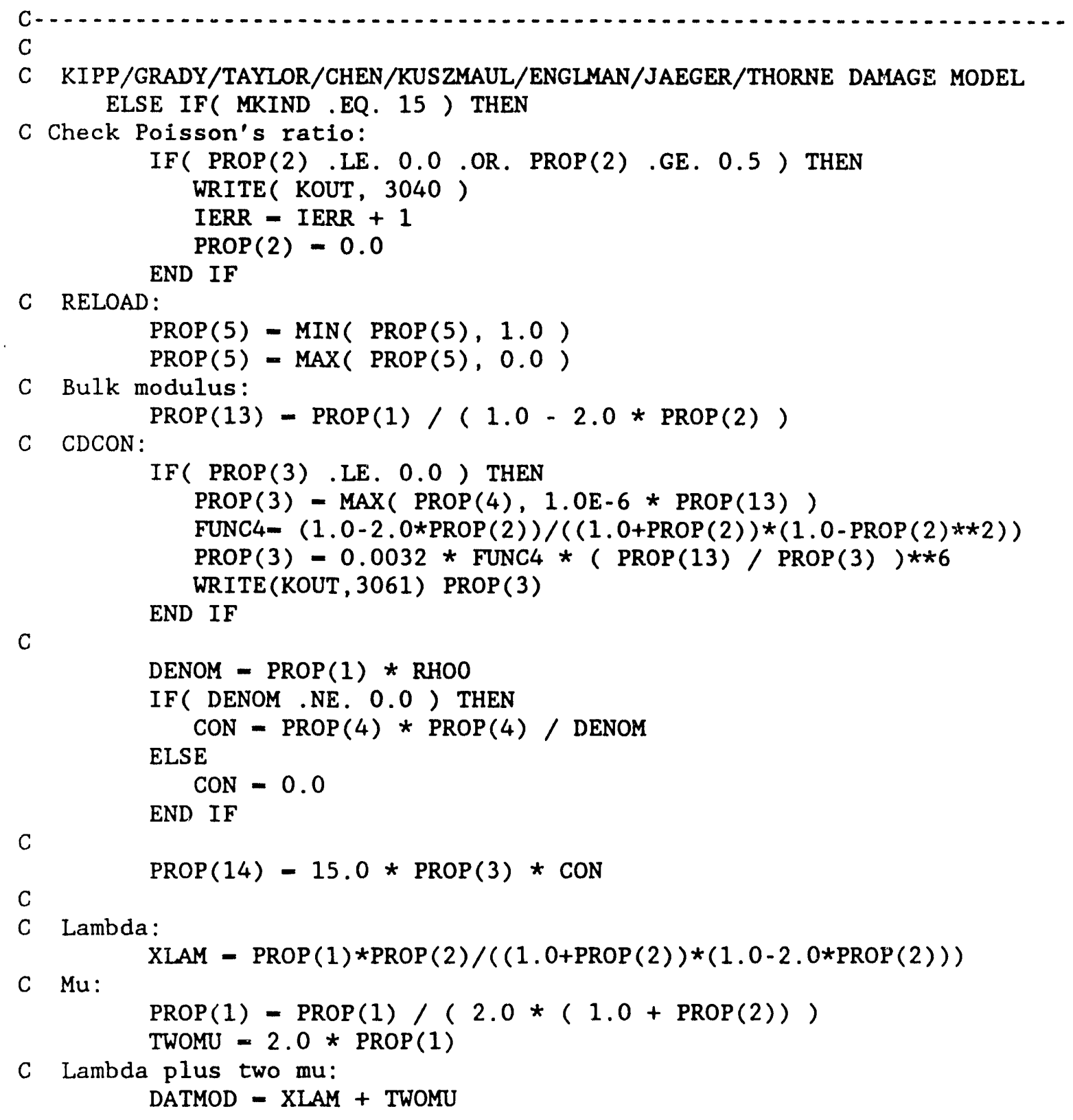


Yield Function Pressures:

P1 - PROP(6) + PROP(9)/3.0

$\mathrm{P} 2$ - PROP(7) + PROP(10)/3.0

$\mathrm{P} 3$ - PROP(8) + PROP(11)/3.0

C CACON:

$\operatorname{PROP}(6)-0.5 * \operatorname{ABS}(20.0 * \operatorname{CON}) * \star(1.0 / 3.0)$

C

C Yield Function:

IF( PROP(9) .EQ. PROP(10) ) THEN

C Perfectly Plastic:

WRITE( KOUT, 3024 )

$\operatorname{PROP}(3)$ - PROP(9)

$\operatorname{PROP}(4)=0.0$

$\operatorname{PROP}(7)-1.0$

$\operatorname{PROP}(8)-1.0$

$\operatorname{PROP}(9)=0.0$

$\operatorname{PROP}(10)=0.0$

$\operatorname{PROP}(11)-\operatorname{PROP}(3) / 3.0$

IF ( PROP (3) . LE. 0.0 ) THEN

WRITE ( KOUT, 3021)

IERR - IERR + 1

END IF

C Linear:

EL.SE IF( PROP(10) .EQ. PROP(11) ) THEN

WRITE ( KOUT, 3025 )

IF ( P1 .EQ. P2 ) THEN

WRITE( KOUT, 3021 )

IERR - IERR + 1

$P 1=1.0$

$P 2=2.0$

END IF

$\operatorname{PROP}(4)=(\operatorname{PROP}(10)-\operatorname{PROP}(9)) /\left(\mathrm{P}_{2}-\mathrm{P} 1\right)$

$\operatorname{PROP}(3)=\operatorname{PROP}(9)-\operatorname{PROP}(4) * \mathrm{ABS}(\mathrm{P} 1)$

$\operatorname{PROP}(7)=1.0$

$\operatorname{PROP}(8)=1.0$

$\operatorname{PROP}(9)=0.0$

$\operatorname{PROP}(10)=0.0$

WRITE ( KOUT, 3026 ) PROP(3), PROP(4)

IF( PROP(4) .GE. 3.0) THEN

WRITE ( KOUT, 3021 )

IERR $=$ IERR + 1

$\operatorname{PROP}(4)=0.1$

END IF

$\operatorname{PROP}(11)=\operatorname{PROP}(3) /(3.0-\operatorname{PROP}(4))$

ELSE 


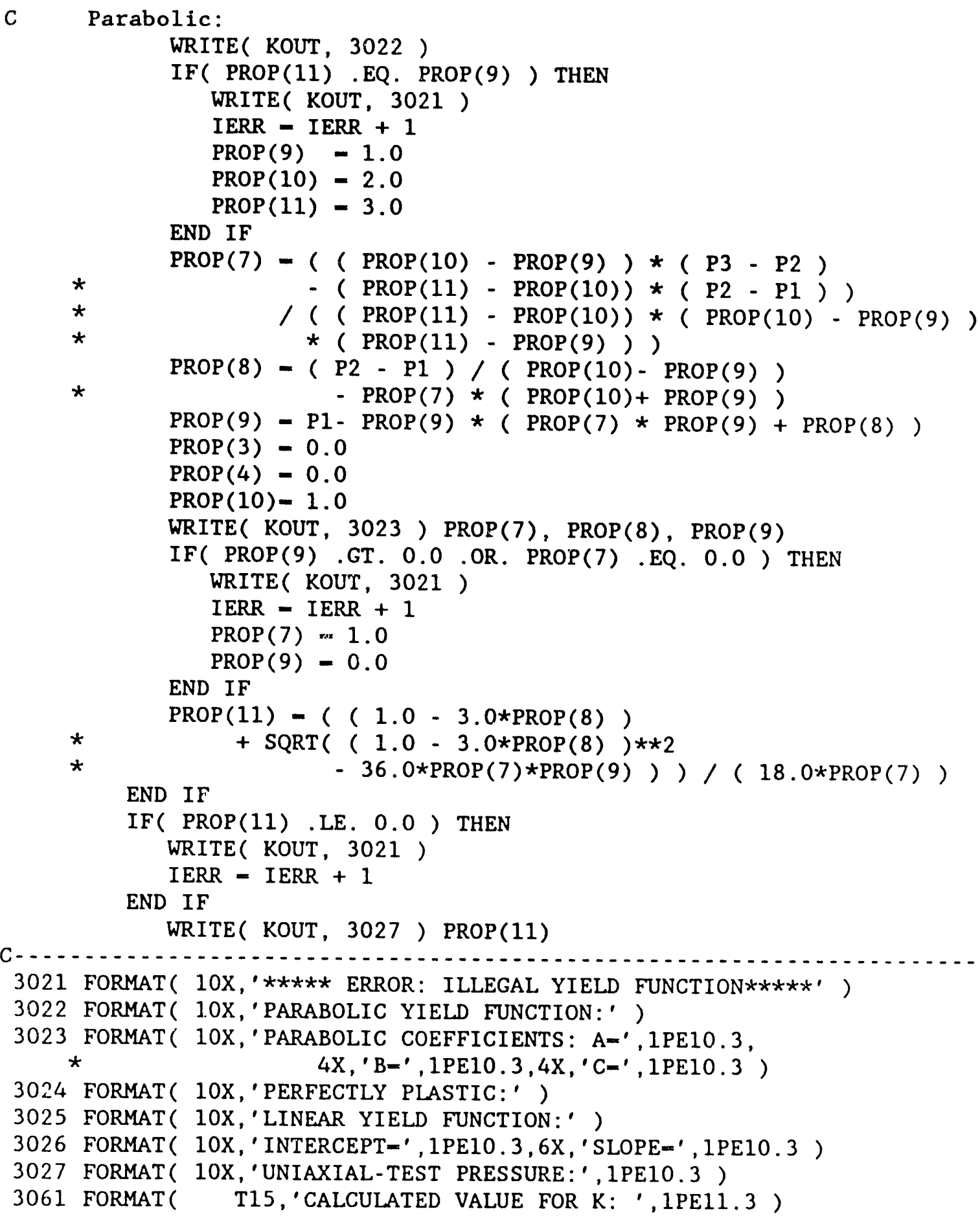


INTENT IONALLY LEFT BLANK 
DAMAGE MODEL SUBROUTINE

SUBROUTINE MAT4A( NBLK, NINSV, DT, PROP, SIG, D, SV, STRAIN )

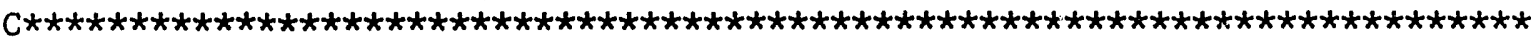

C

KIPP/GRADY/TAYLOR/CHEN/KUSZMAUL/ENGLMAN/JAEGER/THORNE DAMAGE MODEL

A damage model based on micro-crack growth and interaction, with Engleman and Jaeger's extension of Budianski and O'Connal's bulk and shear moduli based on crack density.

Reloading of damaged material uses a fraction of the damage to reduce the bulk modulus. Strain must exceed maximum strain before damage can increase.

Plasticity is used with yield radius a function of volumetric stress, P:

The linear option, $Y(P)=Y I E L D+D Y D P \star A B S(P)$, is based on a line through the maximum stress difference for two triaxial tests showing plastic behavior. The zero pressure intercept of this line is YIELD and its slope is DYDP. YIELD and DYDP must be greater than 0 and DYDP less than 3 .

DYDP-0 for perfectly plastic.

The parabolic option, $\mathrm{Y}(\mathrm{P})-(\mathrm{SQRT}(\mathrm{B} * * 2+4 * \mathrm{~A} *(\mathrm{ABS}(\mathrm{P})+\mathrm{C}))-\mathrm{B}) / 2 * \mathrm{~A}$, is based on an inverse parabola through the maximum stress difference for three triaxial tests showing plastic behavior; $-P(Y)=A * Y * * 2+B * Y+C$.

Yield radius is multiplied by 1 el2 at stresses above that corresponding to zero confining pressure.

FORMAL PARAMETERS :

NBLK INTEGER Number of Elements in this Block

NINSV INTEGER Number of Internal State Variables

DT REAL Time Increment

PROP REAL Material Properties

SIG REAL Stresses

D REAL Strain Rates

STRAIN REAL Strains

SV REAL

Internal Stãe Variables:

$(1, *)$ = damage

$(2, *)$ - maximum volumetric strain rate

$(3, *)$ - maximum volumetric strain

$(4, *)$ - crack density

$(5, *)$ - equivalent plastic strain

$(6, *)$ - fragment size rate factor

CALLED BY: UPDSTR 


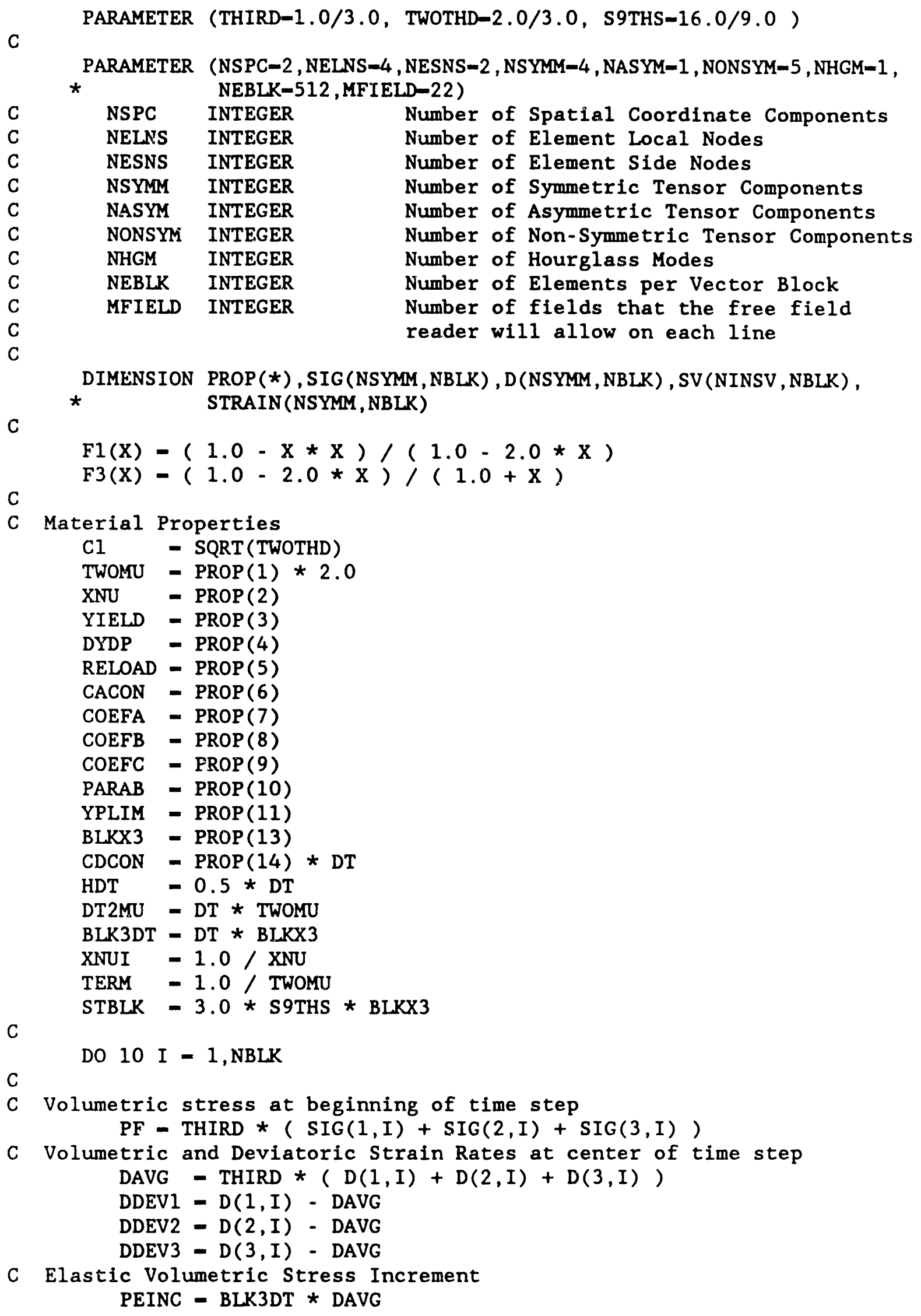


C Update Strains to center of time step

$$
\operatorname{STRAIN}(1, I)-\operatorname{STRAIN}(1, I)+H D T * D(1, I)
$$

$\operatorname{STRAIN}(2, I)-\operatorname{STRAIN}(2, I)+\operatorname{HDT} * D(2, I)$

$\operatorname{STRAIN}(3, I)-\operatorname{STRAIN}(3, I)+\operatorname{HDT} * D(3, I)$

$\operatorname{STRAIN}(4, I)-\operatorname{STRAIN}(4, I)+\mathrm{HDT} * \mathrm{D}(4, \mathrm{I})$

C Volumetric and Deviatioric Total Strains at center of time step

EAVG $-\operatorname{THIRD} *(\operatorname{STRAIN}(1, I)+\operatorname{STRAIN}(2, I)+\operatorname{STRAIN}(3, I))$

EDEV1 - $\operatorname{STRAIN}(1, I)$ - EAVG

$\operatorname{EDEV} 2-\operatorname{STRAIN}(2, I)$ - EAVG

$\operatorname{EDEV} 3$ - $\operatorname{STRAIN}(3, I)$ - EAVG

$\operatorname{EDEV} 4$ - $\operatorname{STRAIN}(4, I)$

C Update Strains to end of time step

$\operatorname{STRAIN}(1, I)-\operatorname{STRAIN}(1, I)+\mathrm{HDT} * \mathrm{D}(1, \mathrm{I})$

$\operatorname{STRAIN}(2, I)-\operatorname{STRAIN}(2, I)+\operatorname{HDT} * D(2, I)$

$\operatorname{STRAIN}(3, I)-\operatorname{STRAIN}(3, I)+\operatorname{HDT} * D(3, I)$

$\operatorname{STRAIN}(4, I)-\operatorname{STRAIN}(4, I)+\operatorname{HDT} * D(4, I)$

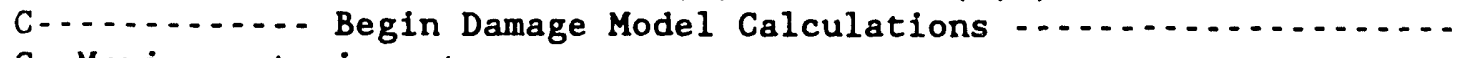

C Maximum strain rate $\operatorname{SV}(2, I)=\operatorname{MAX}(\operatorname{SV}(2, I), \operatorname{DAVG})$

$\operatorname{EINV}-1.0 /(\operatorname{SV}(2, I) * \operatorname{SV}(2, I))$

C Update Multiplier for Average Fragment Size $\operatorname{SV}(6, I)=$ CACON $*$ EINV $* *$ THIRD

C RFAC - 1: When expanding at center of time step RFAC $-0.5+\operatorname{SIGN}(0.5$, DAVG )

C EFAC - 1: When expanded beyond previous maximum strain at center of time step $\operatorname{EFAC}=0.5+\operatorname{SIGN}(0.5, \operatorname{EAVG}-\operatorname{SV}(3, I))$

C Update maximum volumetric strain $\operatorname{SV}(3, I)-\operatorname{MAX}(\operatorname{SV}(3, I), \operatorname{EAVG})$

C PFAC -1 : When in tension at center of time step DFAK - $1.0-\mathrm{SV}(1, \mathrm{I}) \star \mathrm{RELOAD}$ PFAC $-0.5+\operatorname{SIGN}(0.5, \mathrm{PF}+0.5 *$ PEINC

* $\quad$ * (RFAC + (1.0-RFAC ) * DFAK ) )

C Damage can occur only when all three conditions are met TFAC - EFAC * RFAC * PFAC

C Crack Density Increment CDINC - TFAC * CDCON * EINV * DAVG * EAVG**5

$C$ Update Crack Density to end of time step $\operatorname{SV}(4, I)-\operatorname{SV}(4, I)+\operatorname{CDINC}$

C Effective Poisson's ratio at center of time step

$C$ Use elastic Poisson's ratio in compression $\mathrm{XNUB}-\mathrm{XNU} \star \operatorname{EXP}(\operatorname{S9THS} *(0.5 \star \operatorname{CDINC}-\mathrm{SV}(4, \mathrm{I})) \star \mathrm{PFAC})$ FUNC3 - F3 ( XNUB )

C Effective Poisson's ratio at end of time step $\mathrm{XNUE}=\mathrm{XNU} * \operatorname{EXP}(-\mathrm{S} 9 \mathrm{THS} * \mathrm{SV}(4, \mathrm{I}))$ FUNC1 - F1( XNUE )

C Damage Increment DINC - TFAC * ( FUNC1 * ( $1.0-\mathrm{XNUE} * \mathrm{XNUI})-\mathrm{SV}(1, \mathrm{I}))$

C Update Damage to end of time step $\operatorname{SV}(1, I)-\operatorname{SV}(1, I)+\operatorname{DINC}$

C Effective damage at center of time step DFAC $=1.0-(\operatorname{SV}(1, I)-0.5 *$ DINC $)$

$C$ Use elastic properties in compression

C EFAK = 1: When at a positive strain at center of time step EFAK $-0.5+\operatorname{SIGN}(0.5$, EAVG )

$C$ Use a fraction of the damage to reduce elastic contracting in tension DFAK $-1.0-(\operatorname{SV}(1, I)-0.5$ * DINC $)$ * RELOAD * PFAC * EFAK 
C Volumetric Stress Increment

PINC $=($ DFAC * PEINC - BLKX3 * EAVG * DINC $) *$ TFAC + DFAK * PEINC * $(1.0-$ TFAC $)$

$C$ Increment of deviatoric stress DMUDT - STBLK $*$ DFAC * CDINC $\star$ XNUB $/(1.0+\mathrm{XNUB}) \star \star 2$

* $\quad-$ BLKX3 3 * FUNC3 3 DINC

SIINC - TFAC * ( DMUDT*EDEV1 + BLK3DT * DFAC * FUNC3 * DDEV1 )

* $+(1.0-$ TFAC $) *$ BLK3DT * DFAK * FUNC3 * DDEV1

S2INC - TFAC * ( DMUDT*EDEV2 + BLK3DT * DFAC * FUNC3 * DDEV2 )

* $+(1.0-$ TFAC $) *$ BLK3DT * DFAK * FUNC3 * DDEV2

S3INC - TFAC * ( DMUDT*EDEV3 + BLK3DT * DFAC * FUNC3 * DDEV3 )

* $\quad+(1.0-$ TFAC $) *$ BLK3DT * DFAK * FUNC3 * DDEV3

S4INC $=$ TFAC * ( DMUDT*EDEV4 + BLK3DT * DFAC * FUNC3 * D $(4, I))$

* $+(1.0-$ TFAC $) *$ BLK3DT * DFAK * FUNC3 3 D $(4, I)$

$C$ Total stress at end of time step

$\operatorname{SIG}(1, I)-\operatorname{SIG}(1, I)+\operatorname{SIINC}+\operatorname{PINC}$

$\operatorname{SIG}(2, I)-\operatorname{SIG}(2, I)+\operatorname{S} 2 I N C+\operatorname{PINC}$

$\operatorname{SIG}(3, I)-\operatorname{SIG}(3, I)+\operatorname{S} 3 I N C+\operatorname{PINC}$

$\operatorname{SIG}(4, I)-\operatorname{SIG}(4, I)+\operatorname{S} 4 \operatorname{INC}$

C

C Radius of yield surface (Parabolic, Linear or Constant)

$\mathrm{PF}-\mathrm{PF}+\mathrm{PINC}$

RADIUS - C1 * ( YIELD + DYDP * ABS $(P F)$

* $\quad+$ PARAB * (SQRT ( COEFB $* 2+4.0 *$ COEFA

* $\quad$ *(ABS(PF) - COEFC $))-$ COEFB )

* /( COEFA + COEFA ) )

C Elastic when below pressure corresponding to uniaxial test

PFAC $-0.5+\operatorname{SIGN}(0.5, \mathrm{PF}+$ YPLIM $)$

RADIUS - RADIUS * ( $1.0+$ PFAC * $1.0 \mathrm{E} 12)$

C Devatoric Trial Stress

TRIALI - SIG(1,I) - PF

TRIAL2 - SIG $(2, I)$ - PF

TRIAL3 - SIG $(3, I)$ - PF

C Magnitude of the Trial Stress

DSMAG-SQRT (TRIAL1 $* * 2+\operatorname{TRIAL2} * * 2+\operatorname{TRIAL} 3 * * 2+2.0 * \operatorname{SIG}(4, \mathrm{I}) \star * 2)$

$C$ Determine the Factor for Plasticity (Zero for Elastic).

DIFF - DSMAG - RADIUS

EFAC $-0.5+\operatorname{SIGN}(0.5$, DIFF $)$

$C$ Determine the addition factor for when DSMAG is Zero.

$C$ Since there is no Plasticity, EFAC will be Zero and ADDFAC One.

ADDFAC = 1.0 - EFAC

DSMAG - DSMAG + ADDFAC

$C$ Plastic relaxation factor XLAM - EFAC * TERM * DIFF

$C$ Update Stresses for Plasticity

TFAC - 1.0 - XLAM * TWOMU / DSMAG

$\operatorname{SIG}(1, \mathrm{I})-$ TFAC * TRIAL1 + PF

$\operatorname{SIG}(2, I)=$ TFAC * TRIAL2 + PF

$\operatorname{SIG}(3, I)=$ TFAC * TRIAL3 + PF

$\operatorname{SIG}(4, I)=\operatorname{TFAC} * \operatorname{SIG}(4, I)$

C Update equivalent plastic strain.

$\operatorname{SV}(5, I)=\operatorname{SV}(5, I)+C 1$ * XLAM

C

10 CONTINUE

C

RETURN

END

B-4 


\section{Distribution:}

H. E. Thomas

Oil, Gas \& Shale Technology

U. S. Dept. of Energy

Mail Stop FE-33, GTN

Washington, DC 20545

Morgantown Energy Technology Center (2)

U. S. Dept. of Energy

P. 0. Box 880

3610 Collins Ferry Road

Morgantown, WV 26507-0880

H. Guthrie

J. Burchfield

C. Roosmagi

Laramie Project office

U. S. Dept. of Energy

P. O. Box 1189

Laramie, WY 82070

J. Virgona

U. S. Dept of Energy

P. 0. Box 2567

Grand Junction, CO 81502

R. Cena

Lawrence Livermore National Laboratory

P. 0. Box 808

Livermore, CA 94550

U. S. Bureau of Mines (3)

Twin Cities Research Center

5629 Minnehaha Ave. South

Minneapolis, MN 55117
S. Crum
S. Rohl
M. Stagg

Hibbit, Karlsson \& Sorrensen, Inc. (2)

100 Medway St.

Providence, RI 02906

L. M. Taylor

D. P. Flanagan

Mike Barber (10)

Atlas Powder Co.

P. O. Box 271

Tamaqua, PA 18252 
K. P. Chong

Directorate of Engineering

National Science Foundation

1800 G Street NW

Washington, DC 20550

Kim D. Basham

2012 Curtis Street

Laramie, Wyoming 82070

R. F. Chiappetta

Blasting Analysis International

1932 South Forth Street, Suite M-31

Allentown, PA 18103

W. L. Fourney

Dept. of Mechanical Engineering

University of Maryland

College Park, MD 20742

C. T. Aimone

Geological Engineering Department

New Mexico Tech

Socorro, NM 87801

Jim Bratton

Applied Research Associates

4300 San Mateo NE

Albuquerque, NM 87110

Tom Ricketts

SAIC

3351 S. Highland Drive, Suite 206

Las Vegas, NV 89109

Mat thew Lewis

MS G787

Los Alamos National Laboratory

Los Alamos, NM 
Sandia Internal:

$\begin{array}{ll}1425 & \text { S. W. Attaway } \\ 1425 & \text { M. L. Blanford } \\ 1425 & \text { J. H. Biffle } \\ 1514 & \text { H. S. Morgan } \\ 1514 & \text { V. L. Bergmann } \\ 1514 & \text { S. N. Burchett } \\ 1514 & \text { C. M. Stone } \\ 1514 & \text { B. J. Thorne (10) } \\ 1514 & \text { E. P. Chen } \\ 1543 & \text { P. Yarrington } \\ 1543 & \text { M. E. Kipp } \\ 1544 & \text { D. E. Grady } \\ 3141 & \text { S. A. Landenberger (5) } \\ 3145 & \text { C. L. Ward (8), For: DOE/OSTI } \\ 3151 & \text { G. C. Claycomb (3) } \\ 6000 & \text { V. L. Dugan, Acting } \\ 6200 & \text { B. W. Marshall, Acting } \\ 6230 & \text { R. K. Traeger } \\ 6231 & \text { M. C. Walck } \\ 6231 & \text { G. J. Elbring } \\ 6232 & \text { W. R. Wawersik } \\ 6232 & \text { D. J. Holcomb } \\ 6232 & \text { W. A. Olsson } \\ 6232 & \text { L. W. Teufel } \\ 6250 & \text { P. J. Hommert } \\ 6253 & \text { D. A. Northrop } \\ 6253 & \text { D. S. Preece (10) } \\ 6253 & \text { N. R. Warpinski } \\ 6258 & \text { P. M. Drozda } \\ 6314 & \text { L. S. Costin } \\ 8241 & \text { M. L. Chiesa } \\ 8241 & \text { K. L. Perano } \\ 8243 & \text { W. E. Mason } \\ 8523-2 & \text { Central Technical Files } \\ & \end{array}$



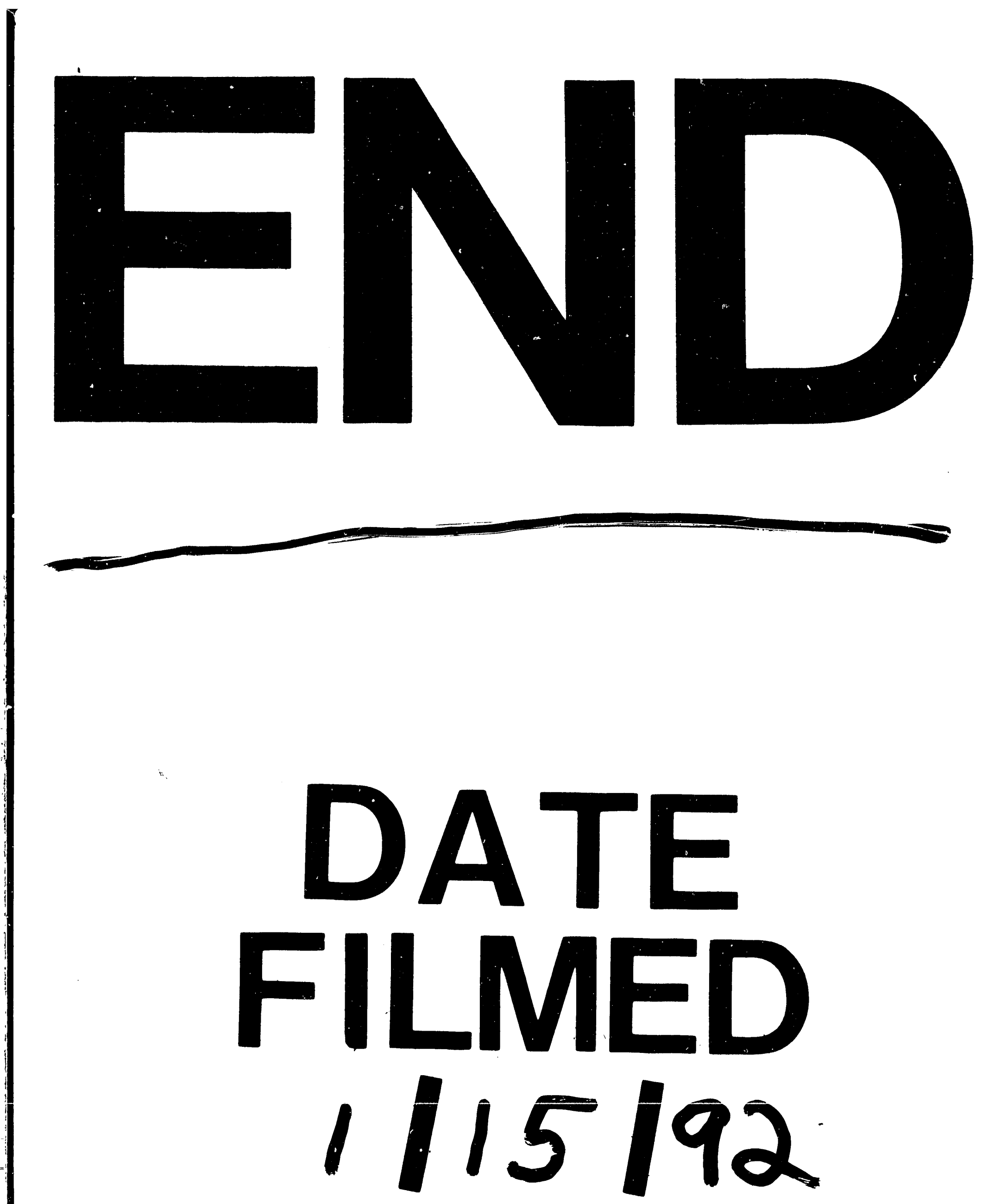
